\title{
Phase stability and microstructures of high entropy alloys ion irradiated to high doses
}

\author{
Songqin Xia ${ }^{\text {a }}$, Michael C. Gao ${ }^{\text {b, c }}$, Tengfei Yang ${ }^{\text {d }}$, Peter K. Liaw ${ }^{\mathrm{e}}$, and Yong Zhang ${ }^{\mathrm{a} *}$ \\ ${ }^{a}$ State Key Laboratory for Advanced Metals and Materials, University of Science and Technology \\ Beijing, Beijing 100083, China \\ ${ }^{\mathrm{b}}$ National Energy Technology Laboratory, 1450 Queen Ave SW, Albany, OR 97321, USA. \\ ${ }^{c}$ AECOM, P.O. Box 1959, Albany, OR 97321, USA \\ ${ }^{\mathrm{d} S t a t e}$ Key Laboratory of Nuclear Physics and Technology, Center for Applied Physics and \\ Technology, Peking University, Beijing 100871, China \\ ${ }^{\text {e} D e p a r t m e n t ~ o f ~ M a t e r i a l s ~ S c i e n c e ~ a n d ~ E n g i n e e r i n g, ~ T h e ~ U n i v e r s i t y ~ o f ~ T e n n e s s e e, ~ K n o x v i l l e, ~}$ \\ TN37996, USA \\ * Correspondence should be addressed to Y. Zhang. (email: drzhangy@ustb.edu.cn).
}

\begin{abstract}
The microstructures of $\mathrm{Al}_{x} \mathrm{CoCrFeNi}(x=0.1,0.75$ and 1.5 in molar ratio) high entropy alloys (HEAs) irradiated at room temperature with $3 \mathrm{MeV} \mathrm{Au}$ ions at the highest fluence of 105, 91, and 81 displacement per atom, respectively, were studied. Transmission electron microscopy (TEM) and high-resolution TEM (HRTEM) analyses show that the initial microstructures and phase composition of all three alloys are retained after ion irradiation and no phase decomposition is observed. Furthermore, it is demonstrated that the disordered face-centered cubic (FCC) and disordered body-centered cubic (BCC) phases show much less defect cluster formation and structural damage than the NiAl-type ordered B2 phase. This effect is explained by higher entropy of mixing, higher defect formation/migration energies, substantially lower thermal conductivity, and higher atomic level stress in the disordered phases.
\end{abstract}

\section{Introduction}

Structural materials used in nuclear reactors must maintain both mechanical performance (strength, ductility, and fracture toughness) and dimensional stability (against creep and void swelling) under irradiation environments of various energetic particles [1-3]. To develop the next-generation nuclear reactor that will be more

\section{$1 / 37$}


efficient and economical and produce less radioactive waste [4], the high-performance structural materials will be required to withstand severer environment, such as higher temperatures and irradiation doses, which exceeds the limits of current nuclear materials. Therefore, the advanced nuclear reactor designs call for dramatic progress in materials, and numerous new materials, such as oxide dispersion steel (ODS) [5], bulk metallic glass (BMG) [6], ceramic materials [7], and bulk nano-layered (NL) composites [8], have been investigated in order to be used in the advanced nuclear reactors [9].

Recently, high entropy alloys (HEAs) [10-16], which are based on the concept of concentrated multi-component solid solution, have shown attractive properties in mitigating irradiation damages, e.g., in CoCrCuFeNi HEA [17], $\mathrm{Al}_{x} \mathrm{CoCrFeNi} H E A s$ $[18,19]$, and refractory HfNbZr medium-entropy alloy [20, 21]. The FCC structure of the as-sputtered $\mathrm{CoCrCuFeNi}$ remained stable against irradiation over a wide temperature range from $298 \mathrm{~K}$ to $773 \mathrm{~K}$ without inducing grain coarsening [17]. The preliminary results by $\mathrm{Xia}$ et al. $[18,19]$ showed that the $\mathrm{Al}_{x} \mathrm{CoCrFeNi}$ alloys exhibited excellent structural stability up to over 50 displacement per atom (dpa) at $298 \mathrm{~K}$, and that the irradiation-induced volume swelling of the FCC solid solution is lower than BCC solid solution, which is in contrast to traditional materials for which the swelling volume in the FCC structure is generally larger than the BCC structure [22]. However, the underlying mechanisms were not understood. Therefore, this study aims to provide more in-depth and thorough TEM and HRTEM studies of their microstructures before and after irradiation, and attempts to rationalize their extraordinary irradiation resistance from the perspectives of lattice phonon vibration, thermal conductivity, and diffusion, and atomic stresses.

\section{Experimental procedures}

The three $\mathrm{Al}_{x} \mathrm{CoCrFeNi}$ alloys with $\mathrm{Al}$ molar ratios of $0.1,0.75$, and 1.5 were synthesized by the vacuum levitation melting (VLM) method [19, 23], and they are referred to as "A10.1", "A10.75", and "A11.5", respectively, in this report. The VLM is

\section{$2 / 37$}


a novel induction melting furnace where the raw metals are levitated in a crucible and alloyed by convective mixing by stirring while under a levitating force. VLM eliminates the contamination from the crucible, and the ingot retains a more uniform microstructure than by the traditional arc-melting technique. These VLM ingots were remelted four times to ensure chemical homogeneity. Melted alloys were eventually drop-cast into a mold $\Phi 80 \times 50 \mathrm{~mm}$. The solidified ingots were cut into thin pieces 1 $\mathrm{mm}$ thick, followed by grinding and polishing. The schematic of the VLM method and bulk HEA sample [23] are shown in Fig. 1.

The microstructure and compositions of as-prepared $\mathrm{Al}_{x} \mathrm{CoCrFeNi}$ HEAs were first characterized by X-ray diffraction (XRD), scanning electronic microscopy (SEM), TEM equipped with energy dispersive X-ray spectroscopy (EDS), and HRTEM. TEM samples were prepared by mechanical polishing to approximately 100 $\mu \mathrm{m}$ thickness, followed by dual jet polishing in an ethanol solution containing 5\% $\mathrm{HClO}_{4}$. To investigate the irradiation responses of the three HEAs, we directly irradiated TEM foils of HEA samples using $3 \mathrm{MeV}$ Au ions at room temperature with fluences ranging from $1 \times 10^{14}$ to $1 \times 10^{16} \mathrm{~cm}^{-2}$ using the $2 \times 1.7 \mathrm{MeV}$ tandem accelerator facility at the Laboratory of Nuclear Physics and Technology in Peking University. The corresponding ion range and dpa are calculated using stopping and range of ions in matter (SRIM) 2008 [24], and the irradiation doses are taken as the average dpa within the depth of $100 \mathrm{~nm}$ that is close to the thicknesses of electron-transparent regions for HRTEM observations and cover all irradiation-affected depths.

The calculated dpa depth (the y-axis on the left and the curves in the red box) and $\mathrm{Au}$-ions deposition profiles (the y-axis on the right and the curves in the blue box) at $1 \times 10^{16} \mathrm{~cm}^{-2}$ are shown in Fig. 2, and the average dpa within the depth of $100 \mathrm{~nm}$ for A10.1, A10.75, and Al1.5 are about $105 \mathrm{dpa}, 91 \mathrm{dpa}$, and $81 \mathrm{dpa}$, respectively. From the Au-ions deposition profile (see the Fig. 2), it is found that the calculated concentration of Au-ions is less than 0.1 at. \% within the depth of $100 \mathrm{~nm}$, although radiation-enhanced diffusional broadening effects may slightly increase the $\mathrm{Au}$ 
concentration at this depth. In order to clarify the microstructural and compositional differences, we used TEM and HRTEM to examine the irradiation-induced defect clusters of $\mathrm{Al}_{x} \mathrm{CoCrFeNi}$ HEAs at the highest fluence of $1 \times 10^{16} \mathrm{~cm}^{-2}$, and the size distributions of defect clusters in Al0.75 and Al1.5 are compared. Moreover, the chemical compositions of pristine and as-irradiated samples were characterized by TEM-EDX.

\section{Results}

\subsection{The characterizations of pristine $\mathrm{Al}_{x} \mathrm{CoCrFeNi} \mathrm{HEAs}$}

Fig. 3 shows the XRD patterns of pristine $\mathrm{Al}_{x} \mathrm{CoCrFeNi}$ HEAs before irradiation. The as-cast microstructures revealed by XRD, SEM, and TEM techniques showed an evolution from a single $\mathrm{FCC}$, to $\mathrm{FCC}+\mathrm{B} 2$, and $\mathrm{B} 2+\mathrm{A} 2$ (disordered $\mathrm{BCC}$ phases) structures with increasing Al contents [19], and this agrees well with prior studies by Yang et al. [25] and Wang et al. [26]. The phase compositions of these three alloys were measured using TEM-EDX, as listed in Table 1. The FCC phase in A10.75 is depleted in $\mathrm{Al}$, while $\mathrm{Ni}$ content is much lower than $\mathrm{Co}, \mathrm{Cr}$ or Fe contents. The B2 phases in Al0.75 and Al1.5 alloys are imperfectly ordered NiAl-type compound with dissolution of $\mathrm{Co}$ and $\mathrm{Fe}$, but depleted in $\mathrm{Cr}$.

The observed microstructures of these three alloys are qualitatively consistent with the equilibrium phase diagrams predicted using PanHEA database [27], shown in Fig. 4. The database has self-consistent thermodynamic descriptions for all constituent binary and ternary systems of Al-Co-Cr-Fe-Ni system. The predicted liquidus temperatures are $1439{ }^{\circ} \mathrm{C}, 1367{ }^{\circ} \mathrm{C}$, and $1491{ }^{\circ} \mathrm{C}$, and the solidus temperatures are $1434{ }^{\circ} \mathrm{C}, 1341{ }^{\circ} \mathrm{C}$, and $1375{ }^{\circ} \mathrm{C}$, respectively, for Al0.1, Al0.75 and Al1.5. The FCC phase is predicted to be stable over a wide temperature range (i.e., $645-1434{ }^{\circ} \mathrm{C}$ ) for Al0.1, but the Al solubility in the FCC phase decreases sharply as the temperature decreases. The FCC phase will decompose to various intermetallics compounds at lower temperatures (e.g., $\leq 500{ }^{\circ} \mathrm{C}$ ), but the kinetics may be extremely slow. The predicted primary crystalline phase is the FCC phase for A10.75 and the B2 phase for 
A11.5. Note that the present experiment did not detect the BCC solid solution phase in the as-cast A10.75, and this could be due to (1) its minor equilibrium amount, and/or (2) fast cooling rate.

\subsection{Irradiation-induced microstructural evolutions in $\mathrm{Al}_{x} \mathrm{CoCrFeNi} \mathrm{HEAs}$}

\subsubsection{Al $l_{0.1} \mathrm{CoCrFeNi}$}

Figs. 5(a-d) compare the microstructures of Al0.1 before and after irradiation test. The bright field (BF) and HRTEM images, combining with the corresponding selected area electron diffraction (SAED) patterns, and fast Fourier Transformations (FFTs) all show that only a single FCC phase formed in the as-cast Al0.1, and it exhibits a great structure stability against ion irradiation. The single FCC phase is essentially preserved, and there is no second phase formation. However, some irradiation-induced defect clusters are formed, as shown in Fig. 5(c), resulting in a serious lattice distortion. Fig. 5(d) presents the HRTEM image, which indicates that besides the irradiation-induced defect clusters, the crystallinity of Al0.1 is also decreased due to ion irradiation, but there is neither ordering nor amorphization, implying great phase stability of the Al0.1 alloy. Moreover, the chemical compositions of ten different regions were measured by TEM-EDX, and the results (Table 1) show that there is no any significant variation in phase composition post irradiation.

\subsection{2 $\mathrm{Al}_{0.75} \mathrm{CoCrFeNi}$}

Figs. 6(a) and 6(b) show that the as-cast A10.75 alloy before irradiation displays an alternating two phase microstructure, which contains the FCC (dark regions) and B2 (bright regions) phases, respectively, as indicated by SAED patterns and HRTEM images. The TEM-EDX characterization results before irradiation are summarized in Table 1, revealing that the $\mathrm{B} 2$ phases are enriched in $\mathrm{Al}$ and $\mathrm{Ni}$, and the FCC phases are enriched in $\mathrm{Fe}, \mathrm{Cr}$ and $\mathrm{Co}$.

The microstructures of A10.75 after irradiated at the highest fluence of $1 \times 10^{16}$ $\mathrm{cm}^{-2}(\sim 91 \mathrm{dpa})$ are presented in Figs. 6(c) and 6(d). BF image and SAED patterns, as 
shown in Fig. 6(c), indicate that the initial microstructure (FCC $+\mathrm{B} 2$ phases) is also preserved, and that there are no detectable new phases forming either. The interfaces between the two phases are still clear, suggesting that the irradiation test did not lead to noticeable phase dissolution. Fig. 6(d) shows the HRTEM image of an interface region between different phases and corresponding FFTs, and the B2 structures as well as the FCC phase are essentially preserved. These observations demonstrate that the A10.75 alloy also exhibits great structure stability against heavy ions irradiation. Again, no significant difference in chemical composition in the FCC and B2 phases can be found between the pristine and irradiated samples (see Table 1).

Moreover, we observed the different response to irradiation in terms of irradiation-induced defect clusters (i.e., those black spots in TEM images in Fig. 6(c)) between the FCC and $\mathrm{B} 2$ phases in A10.75. The defect clusters in the $\mathrm{B} 2$ phase are indicated by the yellow ellipses, and those in the FCC phase are marked by the red squares (see Fig. 6(c)). By counting the number of defect clusters with respect to their sizes for each phase, we obtained the statistical distribution of the defect clusters (see Fig. 6(e)). The plot clearly indicates that the defect clusters in the FCC phase distribute at much smaller sizes with significantly lower frequencies than those in the B2 phase. The defect cluster frequency of the FCC phase (or the B2 phase) shown in Fig. 6(e) refers to the percentage ratio of the number of defect clusters observed in the FCC phase (or the B2 phase) over the total number of defect clusters in both FCC and B2 phases at a fixed defect cluster size.

\subsection{3 $\mathrm{Al}_{1.5} \mathrm{CoCrFeNi}$}

For the Al1.5 alloy before irradiation, a representative BF image (Fig. 7(a)) shows that numerous spherical A2 precipitates with an average diameter of $\sim 80 \mathrm{~nm}$ coherently distribute throughout the B2 matrix, which is consistent with the XRD result [19] and Refs. [25, 26, 28]. Figs. 7(c) and 7(d) show the BF and HRTEM images of Al1.5 after irradiated at $\sim 81 \mathrm{dpa}$. It can be observed that the initial

microstructure (B2 + A2 phases) is well preserved, and no significant ion irradiation-induced mixing between phases occurred. Both A2 and B2 phases remain 
crystalline, and their compositions differ very little from those before irradiation within experimental error range (see Table 1). The crystallinity of the A2 phase is also decreased due to ion irradiation, but no ordering or phase transformation was observed within the A2 phase. Both SAED patterns before and after irradiation reveal that the Al1.5 exhibits great structure stability against heavy Au-ions irradiation. Furthermore, it is worth noting that the defect clusters in the disordered BCC phase distribute at much smaller sizes with significantly lower frequencies than those in the B2 phase. The defect cluster frequency of the A2 phase (or the B2 phase) shown in Fig. 7(e) refers to the percentage ratio of the number of defect clusters observed in the A2 phase (or the B2 phase) over the total number of defect clusters in both A2 and B2 phases at a fixed defect cluster size.

\section{Discussion}

In the present work, we used the step-height measurements $[29,30]$ to determine the volume swellings of the three $\mathrm{Al}_{x} \mathrm{CoCrFeNi}$ HEAs. The sample (size $=5 \mathrm{~mm} \times 5$ $\mathrm{mm} \times 1 \mathrm{~mm}$ ) surfaces were partially masked by Al foils during Au-ions irradiation, and the irradiated region became elevated with respect to the adjacent masked region surface. Hence, the height difference $(\Delta H)$ between the bombarded and protected regions can be measured using atomic force microscopy (AFM), and the volume swelling is quantified based on the step height divided by the nominal damage range ( $400 \mathrm{~nm}$, based on simulations using the SRIM code) following the ASTM standard E521-96 [31]; more details can be found in the previous work [19].

The volume swelling is the lowest for the FCC A10.1 alloy, followed by A10.75, and then A11.5, although the highest dpa was applied for A10.1. A10.75 contains the FCC and B2 phases, while A11.5 contains the B2 and BCC phases. Our TEM analyses show that the disordered solid solution FCC and BCC phases exhibit much less irradiation-induced defect clusters and structural damage than the ordered B2 phase. For example, Figs. 6(e) and 7(e) show that the defect clusters in the disordered FCC or BCC phases distribute at much smaller sizes with significantly lower frequencies 
than those in the B2 phase. While A10.1 is a single disordered solid solution FCC phase, the composite structures and elemental partitioning among phases in A10.75 and Al1.5 render them lower entropies of mixing than A10.1. Here we attempt to explain our observation from the perspectives of defect formation energy, defect migration energy, diffusion, thermal conductivity, and atomic stress.

Aidhy et al. [32] reported that the defect migration barriers and extended defect formation energies are higher in the multi-component disordered solid solution alloys than the pure metal, and their work hint that the defect concentration generated due to irradiation in FCC HEAs may be lower than that in traditional low-entropy alloys. Furthermore, many investigations [33-37] have shown that atomic diffusion in multi-component disordered solid solution HEA is suppressed, resulting in much lower atomic mobilities. Tsai et al. [37] reported the sluggish diffusion in disordered $\mathrm{CoCrFeMnNi} \mathrm{HEA} \mathrm{in} \mathrm{comparison} \mathrm{with} \mathrm{pure} \mathrm{metals} \mathrm{and} \mathrm{low-entropy} \mathrm{alloys,} \mathrm{and}$ proposed that great fluctuation of lattice potential energy causes the significant atomic traps and blocks, leading to the high activation energies and low diffusion nobilities. Lower atomic mobilities in disordered solid solution HEAs than low-entropy alloys (including ordered compounds) may partly contribute to the greater resistance to irradiation than the latter.

Moreover, the molecular dynamics (MD) simulations [32, 38, 39] also show that the mobility of defects is lower in multi-component solid solution than in pure metals, and the formation of large extended defects is suppressed in multi-component disordered solid solution alloys. Jin et al. [40] has also shown that the volume swelling is reduced with increasing the number elements in disordered solid solution, which hints that the volume swelling is closely related to the entropy of mixing of the solid solution. In short, it is tempting to conclude that lower mobilities in the disorder phase hinder the defects movement and growth, resulting in smaller damage structures in disordered phase.

Zhang et al. [41] shows that the different elements in disordered solid solution alloys can sit randomly in the crystal lattice, giving rise to extreme disturbance of 
local atomic, electronic, and lattice structures. Thus, another important physical feature that is unique to high-entropy solid solution alloys is their tremendously reduced thermal conductivity. For conventional metals and alloys, the electron contribution dominates the thermal conductivity. Since conventional BCC alloys, such as, 9-12\%Cr-Mo steels, have much higher thermal conductivities and lower thermal expansion coefficients $[42,43]$ than the austenite steels, the former often demonstrate significantly better irradiation resistance to volume swelling than the latter $[5,22,44,45]$. However, for HEAs, phonon contribution to the thermal conductivity becomes very important as revealed by Chou et al. [46] who measured the electrical resistance, thermal conductivity, and coefficient of thermal expansion of $\mathrm{Al}_{x} \mathrm{CoCrFeNi}$ alloys. They found that the ratios of phonon contribution over electron contribution are $0.68-0.64,1.33-1.19$, and 2.66-2.20 for $x=0,0.75$, and 1.5, respectively. Furthermore, the extreme disorder in HEAs decreases the mean free path of energy carriers and thus tremendously reduces thermal conductivity [41]. For example, the measured thermal conductivities are $11.6,10.5$, and $19.3 \mathrm{~W} / \mathrm{m} / \mathrm{K}$ at $\mathrm{T}=$ $298 \mathrm{~K}$ for $x=0,0.75$, and 1.5 , respectively, which are almost one order of magnitude lower than the estimated values using the rule of mixture.

The significantly reduced thermal conductivity in HEAs and increased phonon contribution may play an important role in their outstanding resistance against irradiation (e.g., the extraordinary phase stability and exceptionally small volume swelling), as observed in this study and others [17, 20, 21, 40, 47]. Ullah et al. [38] has reported that the disordered electrons in disordered solid solution alloys can significantly reduce the local heat conduction, and consequently, they keep the damaging energy longer at the deposition locations, and thus favor defect recombination. Phonon conductivity is very important in thermal spikes in collision cascades which usually occur in short time scale of picoseconds. A recent theoretical study using non-equilibrium molecular dynamics by Caro et al. [48] confirmed that disordering in a solid solution favors reduction of the thermal conductivity and 
showed that the alloy components and compositions can be tailored to minimize thermal conductivity.

Al effect on the lattice stability in HEAs is reviewed in Ref. [49]. Since the Al atom has significantly larger atomic diameter than a $\mathrm{Co}, \mathrm{Cr}, \mathrm{Fe}$ or $\mathrm{Ni}$ atom and a $\mathrm{BCC}$ lattice is more open and has a lower packing efficiency than an FCC lattice, the resulting atomic stress exerted on the host atoms by inserting $\mathrm{Al}$ atoms in an $\mathrm{FCC}$ lattice of $3 \mathrm{~d}$ transition metals is much larger than the case of a BCC lattice consisting of the same elements. As a result, $\mathrm{Al}$ acts a potent $\mathrm{BCC}$ stabilizer for transition metals [49]. Atomic stress is due to the mismatch in atomic size and the electron charge transfer among constituent elements [50]. High atomic stress in HEAs may facilitate amorphorization upon irradiation [17]. In fact, Egami et al. [50] calculated the atomic stress for $\mathrm{Cr}$ atoms to be $-37.55 \mathrm{GPa}$ (i.e., under tension) and +35.16 GPa (i.e., under compression) for $\mathrm{Ni}$ atoms in CoCrFeNi HEA. Particle irradiation with large amount of kinetic energy could locally melt the lattice, followed by quick local recrystallization [50] which may remove much of structural defects and accordingly result in so-called "self-healing" effect.

The purpose of this study was to examine the microstructural evolution of $\mathrm{Al}_{x} \mathrm{CoCrFeNi} \mathrm{HEAs}$ under $\mathrm{Au}$ ion irradiation at room temperature using TEM and HRTEM, and this study revealed that all three alloys showed good structural stability with irradiation up to high dose (over $80 \mathrm{dpa}$ ). However, in order to evaluate if $\mathrm{Al}_{x} \mathrm{CoCrFeNi}$ and other HEAs are competitive candidates for modern nuclear energy applications, ion irradiation at elevated temperatures are necessary since typical irradiation temperatures are $\sim 300{ }^{\circ} \mathrm{C}$ for light water reactors and $300-800{ }^{\circ} \mathrm{C}$ for fusion and Gen IV fission applications [51, 52]. Furthermore, it is known that typical irradiation-induced structural damages (e.g., irradiation-induced solute segregation, voids, and precipitation) are only observed during irradiation at higher temperatures near 0.35-0.6 $\mathrm{T}_{M}$ (where $\mathrm{T}_{M}$ is the melting temperature) $[45,53]$. As a matter of fact, Kiran Kumar et al. [51] studied the microstructural evolution of an FCC CrFeMnNi HEA under ion irradiation with $0.03-10 \mathrm{dpa}$ from room temperature to $700{ }^{\circ} \mathrm{C}$, and 
they did not observe void or phase transformation at all temperatures except high-density small dislocation loops and noticeable irradiation-induced hardening. They concluded that the alloy demonstrated superior irradiation resistance compared to conventional single phase $\mathrm{Fe}-\mathrm{Cr}-\mathrm{Ni}$ austenite alloys such as stainless steels, primarily due to severe lattice distortion and sluggish diffusion that are unique to HEAs.

\section{Conclusions}

Three HEAs $\mathrm{Al}_{x} \mathrm{CoCrFeNi}(x=0.1,0.75$ and 1.5) were irradiated with $3 \mathrm{MeV}$ $\mathrm{Au}$ ions at the highest fluence of $1 \times 10^{16} \mathrm{~cm}^{-2}$, and the microstructures and chemical compositions of as-irradiated HEAs were characterized by TEM and HRTEM. We have demonstrated that there is no significant ordering, amorphization, or phase separation, pointing to great phase stability of these three alloys under heavy ion irradiation at at room temperature to high dpa. Moreover, quantitative comparison of the defect cluster sizes in Al0.75 and Al1.5 HEAs reveals that the defect clusters in the disordered FCC and disordered BCC phase distribute at much smaller sizes with significantly lower frequencies than those in the ordered B2 phase. This effect may be explained by reduced defects mobility (or high defect formation/migration energies) in the disordered phase. Furthermore, tremendously reduced thermal conductivity and large atomic stress in disordered high-entropy solid solution may promote "self-healing" effect.

\section{Acknowledgment}

The authors appreciate the National Science Foundation of China (No. 51471025) and 111 Project (B07003). M.C.G. acknowledges support by the Cross-Cutting Technologies Program of National Energy Technology Laboratory under the RES contract DE-FE-0004000. P.K.L. very much appreciates the financial support from the US National Science Foundation (CMMI-1100080) and the US Army Research Office (W911NF-13-1-0438). 


\section{Disclaimer}

This project was funded by the Department of Energy, National Energy Technology Laboratory, an agency of the United States Government, through a support contract with AECOM. Neither the United States Government nor any agency thereof, nor any of their employees, nor AECOM, nor any of their employees, makes any warranty, expressed or implied, or assumes any legal liability or responsibility for the accuracy, completeness, or usefulness of any information, apparatus, product, or process disclosed, or represents that its use would not infringe privately owned rights. Reference herein to any specific commercial product, process, or service by trade name, trademark, manufacturer, or otherwise, does not necessarily constitute or imply its endorsement, recommendation, or favoring by the United States Government or any agency thereof. The views and opinions of authors expressed herein do not necessarily state or reflect those of the United States Government or any agency thereof. 


\section{References}

[1] T. Allen, J. Busby, M. Meyer, D. Petti, Materials challenges for nuclear systems, Mater. Today 13 (2010) 14-23.

[2] Y. Guérin, G.S. Was, S.J. Zinkle, Materials challenges for advanced nuclear energy systems, MRS Bull. 34 (2009) 10-14.

[3] P. Yvon, F. Carre, Structural materials challenges for advanced reactor systems, J. Nucl. Mater. 385 (2009) 217-222.

[4] K.L. Murty, I. Charit, Structural materials for Gen-IV nuclear reactors: Challenges and opportunities, J. Nucl. Mater. 383 (2008) 189-195.

[5] G.R. Odette, M.J. Alinger, B.D. Wirth, Recent developments in irradiation-resistant steels, Annu. Rev. Mater. Res. 38 (2008) 471-503.

[6] B. Wang, X. Mei, H. Zhang, W. Hou, Y. Wang, Z. Wang, C. Dong, Resistance to $\mathrm{He}^{2+}$ induced irradiation damage in metallic glass $\mathrm{Zr}_{64} \mathrm{Cu}_{17.8} \mathrm{Ni}_{10.7} \mathrm{Al}_{7.5}$, J. Nucl. Mater. 444 (2014) 342-348.

[7] L.W. Hobbs, F.W. Clinard, Jr., S.J. Zinkle, R.C. Ewing, Radiation effects in ceramics, J. Nucl. Mater. 216 (1994) 291-321.

[8] W.Z. Han, M.J. Demkowicz, N.A. Mara, E.G. Fu, S. Sinha, A.D. Rollett, Y.Q. Wang, J.S. Carpenter, I.J. Beyerlein, A. Misra, Design of Radiation Tolerant Materials Via Interface Engineering, Adv. Mater. 25 (2013) 6975-6979.

[9] M.J. Demkowicz, P. Bellon, B.D. Wirth, Atomic-scale design of radiation-tolerant nanocomposites, MRS Bull. 35 (2010) 992-998.

[10] Y. Yokoyama, S. Itoh, Y. Murakami, I. Narita, G. Wang, P.K. Liaw, Microsegregation in and phase stability of as-cast Ti-Zr-Hf-Ni-Pd-Pt high-entropy alloys, Metall. Mater. Trans. A 46 (2014) 1474-1480.

[11] B. Cantor, I.T.H. Chang, P. Knight, A.J.B. Vincent, Microstructural development in equiatomic multicomponent alloys, Mater. Sci. Eng., A 375 (2004) 213-218.

[12] Y. Zhang, T.T. Zuo, Z. Tang, M.C. Gao, K.A. Dahmen, P.K. Liaw, Z.P. Lu, Microstructures and properties of high-entropy alloys, Prog. Mater. Sci. 61 (2014) $1-93$. 
[13] J.W. Yeh, S.K. Chen, S.J. Lin, J.Y. Gan, T.S. Chin, T.T. Shun, C.H. Tsau, S.Y. Chang, Nanostructured high-entropy alloys with multiple principal elements: novel alloy design concepts and outcomes, Adv. Eng. Mater. 6 (2004) 299-303.

[14] L.J. Santodonato, Y. Zhang, M. Feygenson, C.M. Parish, M.C. Gao, R.J.K. Weber, J.C. Neuefeind, Z. Tang, P.K. Liaw, Deviation from high-entropy configurations in the atomic distributions of a multi-principal-element alloy, Nat. Commun. 6 (2015).

[15] Y. Zhang, Y.J. Zhou, J.P. Lin, G.L. Chen, P.K. Liaw, Solid-solution phase formation rules for multi-component alloys, Adv. Eng. Mater. 10 (2008) 534-538.

[16] M.C. Gao, P.K. Liaw, J.-W. Yeh, Y. Zhang, High-Entropy Alloys: Fundamentals and Applications, 1st ed., Springer International Publishing, Cham, Switzerland, 2016. [17] T. Nagase, P.D. Rack, J.H. Noh, T. Egami, In-situ TEM observation of structural changes in nano-crystalline $\mathrm{CoCrCuFeNi}$ multicomponent high-entropy alloy (HEA) under fast electron irradiation by high voltage electron microscopy (HVEM), Intermetallics 59 (2015) 32-42.

[18] S.Q. Xia, Z. Wang, T.F. Yang, Y. Zhang, Irradiation behavior in high entropy alloys, J. Iron Steel Res. Int. 22 (2015) 879-884.

[19] S.Q. Xia, X. Yang, T.F. Yang, S. Liu, Y. Zhang, Irradiation resistance in $\mathrm{Al}_{x} \mathrm{CoCrFeNi}$ high entropy alloys, Jom. 67 (2015) 1-5.

[20] T. Nagase, S. Anada, P.D. Rack, J.H. Noh, H. Yasuda, H. Mori, T. Egami, Electron-irradiation-induced structural change in $\mathrm{Zr}-\mathrm{Hf}-\mathrm{Nb}$ alloy, Intermetallics 26 (2012) 122-130.

[21] T. Nagase, S. Anada, P.D. Rack, J.H. Noh, H. Yasuda, H. Mori, T. Egami, MeV electron-irradiation-induced structural change in the bcc phase of $\mathrm{Zr}-\mathrm{Hf}-\mathrm{Nb}$ alloy with an approximately equiatomic ratio, Intermetallics 38 (2013) 70-79.

[22] R.L. Klueh, A.T. Nelson, Ferritic/martensitic steels for next-generation reactors, J. Nucl. Mater. 371 (2007) 37-52.

[23] Y. Zhang, J.W. Qiao, P.K. Liaw, A brief review of high entropy alloys serration behavior and flow units, J. Iron Steel Res. Int. 23 (2016) 2-6.

[24] J.F. Ziegler, M.D. Ziegler, J.P. Biersack, SRIM, the stopping and range of ions in 
matter, (2008).

[25] T.F. Yang, S.Q. Xia, S. Liu, C.X. Wang, S.S. Liu, Y. Zhang, J.M. Xue, S. Yan, Y.G. Wang, Effects of $\mathrm{Al}$ addition on microstructure and mechanical properties of $\mathrm{Al}_{x} \mathrm{CoCrFeNi}$ high-entropy alloy, Mater. Sci. Eng., A 648 (2015) 15-22.

[26] W.R. Wang, W.L. Wang, J.W. Yeh, Phases, microstructure and mechanical properties of $\mathrm{Al}_{x} \mathrm{CoCrFeNi}$ high-entropy alloys at elevated temperatures, J. Alloys Compd. 589 (2014) 143-152.

[27] Pandat ${ }^{\mathrm{TM}}$, Thermodynamic Calculations and Kinetic Simulations, CompuTherm LLC, Madison, WI - 53719.

[28] W.R. Wang, W.L. Wang, S.C. Wang, Y.C. Tsai, C.H. Lai, J.W. Yeh, Effects of Al addition on the microstructure and mechanical property of $\mathrm{Al}_{x} \mathrm{CoCrFeNi}$ high-entropy alloys, Intermetallics 26 (2012) 44-51.

[29] W.G. Johnston, J.H. Rosolowski, A.M. Turkalo, T. Lauritzen, A direct measurement of gross swelling in nickel-ion-bombarded stainless steel, J. Nucl. Mater. 46 (1973) 273-280.

[30] K. Jin, C. Lu, L.M. Wang, J. Qu, W.J. Weber, Y. Zhang, H. Bei, Effects of compositional complexity on the ion-irradiation induced swelling and hardening in Ni-containing equiatomic alloys, Scr. Mater. 119 (2016) 65-70.

[31] ASTM E521, Standard Practice for Neutron Radiation Damage Simulation by Charged-Particle Irradiation, 2009.

[32] D.S. Aidhy, C. Lu, K. Jin, H. Bei, Y. Zhang, L. Wang, W.J. Weber, Point defect evolution in $\mathrm{Ni}, \mathrm{NiFe}$ and $\mathrm{NiCr}$ alloys from atomistic simulations and irradiation experiments, Acta Mater. 99 (2015) 69-76.

[33] S.Y. Chang, C.Y. Wang, M.K. Chen, C.E. Li, Ru incorporation on marked enhancement of diffusion resistance of multi-component alloy barrier layers, J. Alloy Compd. 509 (2011) L85-L89.

[34] S.Y. Chang, C.E. Li, S.C. Chiang, Y.C. Huang, 4-nm thick multilayer structure of multi-component (AlCrRuTaTiZr) $\mathrm{N}_{x}$ as robust diffusion barrier for $\mathrm{Cu}$ interconnects, J. Alloy Compd. 515 (2012) 4-7. 
[35] S.Y. Chang, D.S. Chen, 10-nm-thick quinary (AlCrTaTiZr)N film as effective diffusion barrier for $\mathrm{Cu}$ interconnects at $900{ }^{\circ} \mathrm{C}$, Appl. Phys. Lett. 94 (2009) 231909. [36] S.Y. Chang, C.E. Li, Y.C. Huang, H.F. Hsu, J.W. Yeh, S.J. Lin, Structural and thermodynamic factors of suppressed interdiffusion kinetics in multi-component high-entropy materials, Sci. Rep. 4 (2014).

[37] K.Y. Tsai, M.H. Tsai, J.W. Yeh, Sluggish diffusion in Co-Cr-Fe-Mn-Ni high-entropy alloys, Acta Mater. 61 (2013) 4887-4897.

[38] M.W. Ullah, D.S. Aidhy, Y. Zhang, W.J. Weber, Damage accumulation in ion-irradiated Ni-based concentrated solid-solution alloys, Acta Mater. 109 (2016) $17-22$.

[39] L.K. Beland, G.D. Samolyuk, R.E. Stoller, Differences in the accumulation of ion-beam damage in $\mathrm{Ni}$ and $\mathrm{NiFe}$ explained by atomistic simulations, J. Alloys Compd. 662 (2016) 415-420.

[40] K. Jin, B.C. Sales, G.M. Stocks, G.D. Samolyuk, M. Daene, W.J. Weber, Y. Zhang, H. Bei, Tailoring the physical properties of Ni-based single-phase equiatomic alloys by modifying the chemical complexity, Sci. Rep. 6 (2016).

[41] Y. Zhang, G.M. Stocks, K. Jin, C. Lu, H. Bei, B.C. Sales, L. Wang, L.K. Béland, R.E. Stoller, G.D. Samolyuk, Influence of chemical disorder on energy dissipation and defect evolution in concentrated solid solution alloys, Nat. Commun. 6 (2015).

[42] M.J. Peet, H.S. Hasan, H. Bhadeshia, Prediction of thermal conductivity of steel, Int. J. Heat Mass Transf. 54 (2011) 2602-2608.

[43] F. Liu, M. Rashidi, L. Johansson, J. Hald, H.-O. Andren, A new 12\% chromium steel strengthened by Z-phase precipitates, Scr. Mater. 113 (2016) 93-96.

[44] D. Faulkner, C.H. Woo, Void swelling in zirconium, J. Nucl. Mater. 90 (1980) 307-316.

[45] S.J. Zinkle, L.L. Snead, Designing radiation resistance in materials for fusion energy*, Annu. Rev. Mater. Res. 44 (2014) 241-267.

[46] H.P. Chou, Y.S. Chang, S.K. Chen, J.W. Yeh, Microstructure, thermophysical and electrical properties in $\mathrm{Al}_{x} \mathrm{CoCrFeNi}(0<=x<=2)$ high-entropy alloys, Mater. Sci. 
Eng., B 163 (2009) 184-189.

[47] T. Egami, W. Guo, P.D. Rack, T. Nagase, Irradiation resistance of multicomponent alloys, Metall. Mater. Trans. A 45 (2014) 180-183.

[48] M. Caro, L.K. Beland, G.D. Samolyuk, R.E. Stoller, A. Caro, Lattice thermal conductivity of multi-component alloys, J. Alloys Compd. 648 (2015) 408-413.

[49] Z. Tang, M.C. Gao, H.Y. Diao, T.F. Yang, J.P. Liu, T.T. Zuo, Y. Zhang, Z.P. Lu, Y.Q. Cheng, Y.W. Zhang, K.A. Dahmen, P.K. Liaw, T. Egami, Aluminum alloying effects on lattice types, microstructures, and mechanical behavior of high-entropy alloys systems, Jom. 65 (2013) 1848-1858.

[50] T. Egami, M. Ojha, O. Khorgolkhuu, D.M. Nicholson, G.M. Stocks, Local electronic Effects and Irradiation Resistance in High-Entropy Alloys, Jom 67 (2015) 2345-2349.

[51] N. Kumar, C. Li, K.J. Leonard, H. Bei, S.J. Zinkle, Microstructural stability and mechanical behavior of FeNiMnCr high entropy alloy under ion irradiation, Acta Mater. 113 (2016) 230-244.

[52] S.J. Zinkle, G.S. Was, Materials challenges in nuclear energy, Acta Mater. 61 (2013) 735-758.

[53] E.A. Kenik, J.T. Busby, Radiation-induced degradation of stainless steel light water reactor internals, Mater. Sci. Eng., R 73 (2012) 67-83. 
Table 1. TEM-EDX results (at. \%) of the pristine and as-irradiated $\mathrm{Al}_{x} \mathrm{CoCrFeNi}$ $(x=0.1, x=0.75$, and 1.5) HEAs.

\begin{tabular}{|c|c|c|c|c|c|c|c|}
\hline Alloys & Microstructure & Conditions & $\mathrm{Al}$ & Co & $\mathrm{Cr}$ & $\mathrm{Fe}$ & $\mathrm{Ni}$ \\
\hline \multirow{3}{*}{ Al0.1 } & FCC & pristine & $1.7 \pm 0.7$ & $25.6 \pm 1.3$ & $22.5 \pm 2.3$ & $25.3 \pm 1.2$ & $24.9 \pm 2.2$ \\
\hline & & & & & & & \\
\hline & FCC & irradiated & $2.5 \pm 0.9$ & $22.9 \pm 1.2$ & $25.9 \pm 1.8$ & $24.2 \pm 1.7$ & $24.5 \pm 2.2$ \\
\hline \multirow{4}{*}{ Al0.75 } & FCC & pristine & $6.2 \pm 0.3$ & $24.4 \pm 2.6$ & $26.1 \pm 3.1$ & $26.2 \pm 3.0$ & $17.1 \pm 3.6$ \\
\hline & FCC & irradiated & $4.6 \pm 1.5$ & $24.4 \pm 1.5$ & $27.4 \pm 1.9$ & $28.5 \pm 1.3$ & $15.1 \pm 2.1$ \\
\hline & B2 & pristine & $32.3 \pm 2.1$ & $17.9 \pm 2.1$ & $5.8 \pm 0.8$ & $12.1 \pm 1.4$ & $31.9 \pm 5.5$ \\
\hline & B2 & irradiated & $33.7 \pm 4.2$ & $17.6 \pm 1.3$ & $5.3 \pm 2.6$ & $11.7 \pm 1.5$ & $31.7 \pm 2.0$ \\
\hline \multirow{4}{*}{ Al1.5 } & $\mathrm{A} 2$ & pristine & $5.1 \pm 1.0$ & $8.8 \pm 0.6$ & $53.1 \pm 4.0$ & $31.9 \pm 4.8$ & $1.1 \pm 0.8$ \\
\hline & A2 & irradiated & $2.1 \pm 2.5$ & $7.7 \pm 3.3$ & $56.4 \pm 5.0$ & $32.8 \pm 3.2$ & $1.0 \pm 1.4$ \\
\hline & B2 & pristine & $40.2 \pm 2.6$ & $21.3 \pm 2.1$ & $3.2 \pm 1.1$ & $11.2 \pm 0.8$ & $24.1 \pm 5.3$ \\
\hline & B2 & irradiated & $37.2 \pm 3.0$ & $22.5 \pm 1.6$ & $4.2 \pm 2.5$ & $13.5 \pm 1.9$ & $22.6 \pm 2.4$ \\
\hline
\end{tabular}




\section{FIGURE CAPTIONS:}

Fig. 1. A schematic of the VLM method and the bulk HEAs sample.

Fig. 2. SRIM simulations of $\mathrm{Al}_{x} \mathrm{CoCrFeNi} \mathrm{HEAs}$ irradiated with $3 \mathrm{MeV} \mathrm{Au}$ ions at the fluence of $1 \times 10^{16}\left(\mathrm{~cm}^{-2}\right)$. The curves in the red box signify the damage distribution, while the curves in the blue box signify the deposited Au-ions concentration (at. \%). Note that the dpa and Au-ions concentration for irradiated TEM foils are estimated according to corresponding average values within the depth of $100 \mathrm{~nm}$.

Fig. 3. XRD patterns of as-cast (a) Al0.1, (b) Al 0.75, and (c) Al1.5 HEAs

Fig. 4. Calculated equilibrium phase diagrams using PanHEA database: (a) the isopleth of temperature vs. Al molar ratio. Phase mole fraction vs. temperature plots for (b) Al0.1, (c) Al0.75, and (d) Al1.5.

Fig. 5. BF and HRTEM images of Al0.1 HEA: (a), (b) pristine state and (c), (d) irradiated with $3 \mathrm{MeV}$ Au ions at $1 \times 10^{16} \mathrm{~cm}^{-2}(\sim 105 \mathrm{dpa})$. The SAED patterns and FFTs (zone axis [100]) before and after irradiation are also given.

Fig. 6. BF and HRTEM images of A10.75 HEA: (a), (b) pristine state and (c), (d) irradiated with $3 \mathrm{MeV}$ Au ions at $1 \times 10^{16} \mathrm{~cm}^{-2}$ ( 91 dpa). (e) Comparison in frequency and size distribution for the defect clusters observed in the disordered FCC and ordered B2 phases. The yellow ellipses in (c) signify the defects in the B2 phase, and the red squares signify the defects in the FCC phase.

Fig. 7. BF and HRTEM images of Al1.5 HEA: (a), (b) pristine state and (c), (d) irradiated with $3 \mathrm{MeV}$ Au ions at $1 \times 10^{16} \mathrm{~cm}^{-2}(\sim 81 \mathrm{dpa})$. (e) Comparison in frequency and size distribution for the defect clusters observed in the disordered BCC and ordered B2 phases. The yellow ellipses in (c) signify the defects in the B2 phase, and the red squares signify the defects in the disordered $\mathrm{BCC}$ phase. 


\section{FIGURES}

Fig. 1.
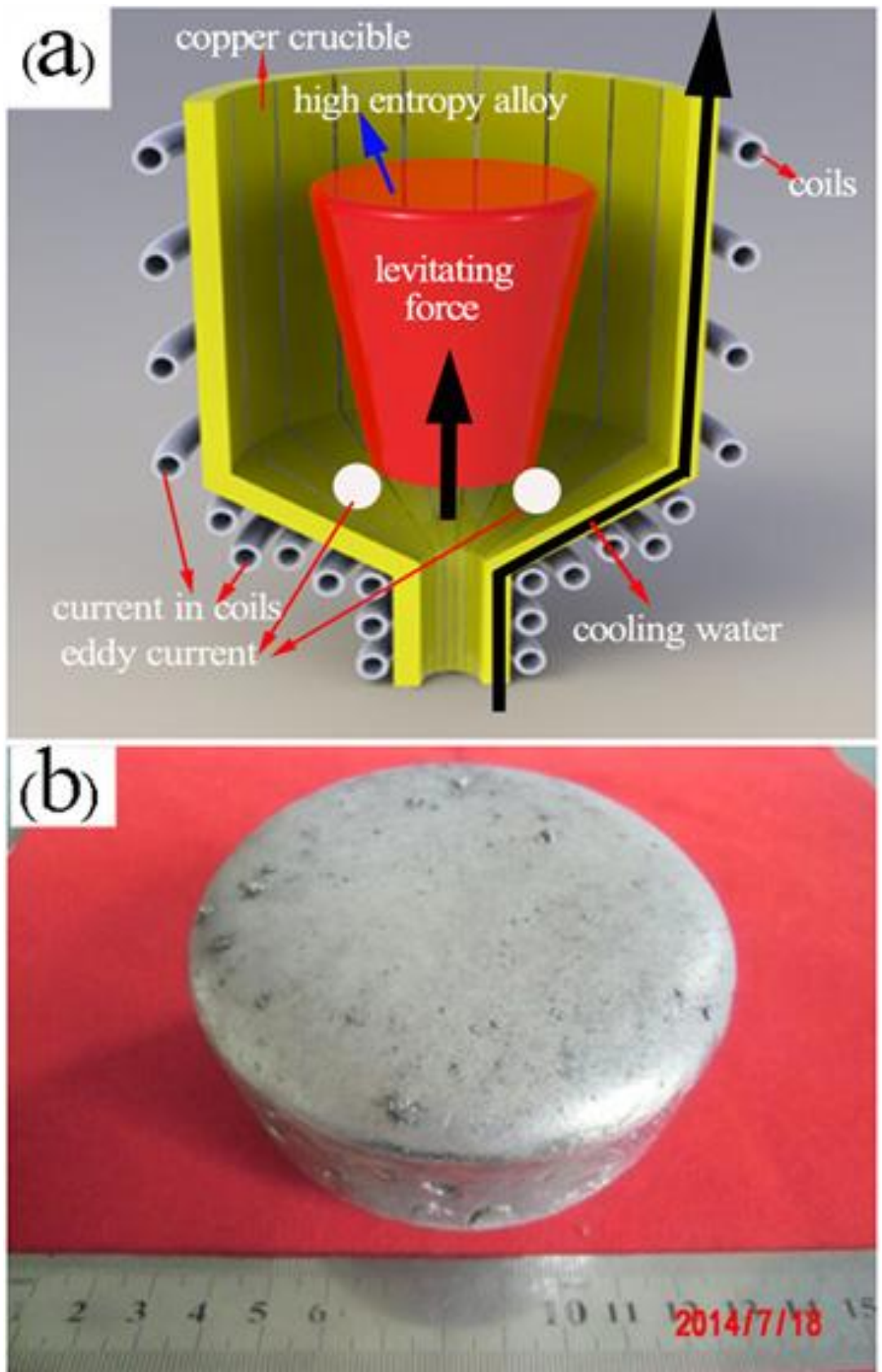
Fig. 2.

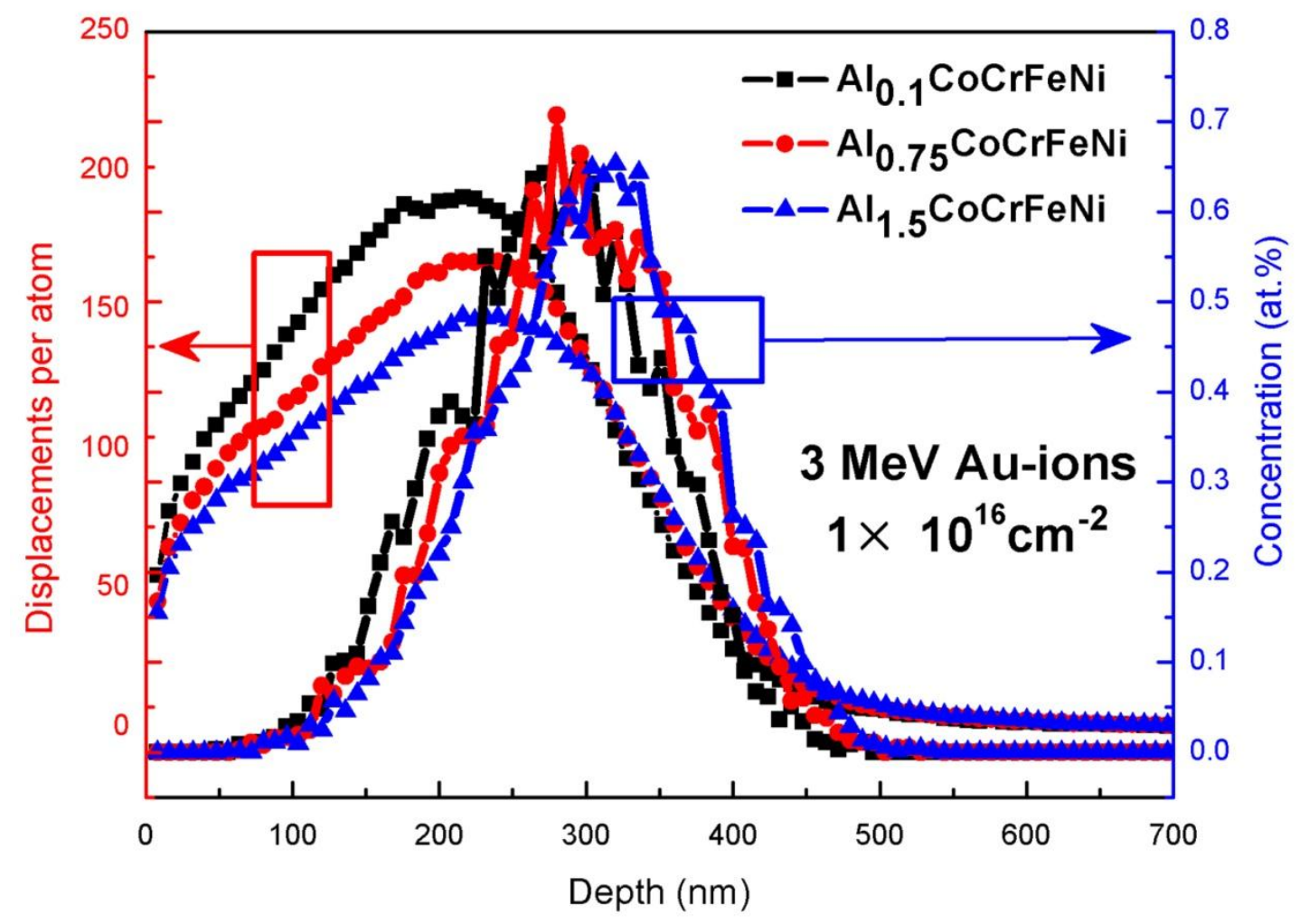


Fig. 3.

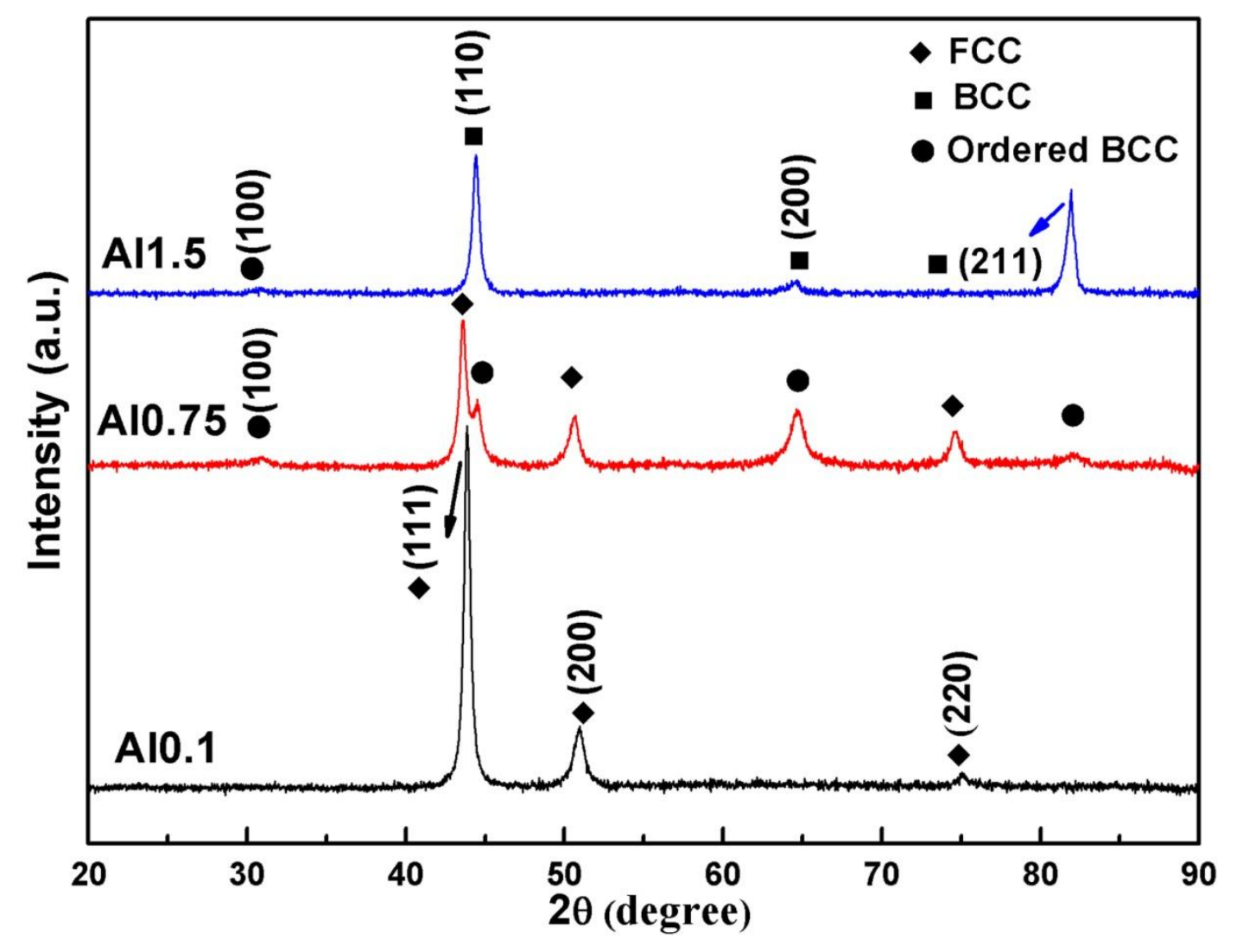


Fig. 4.
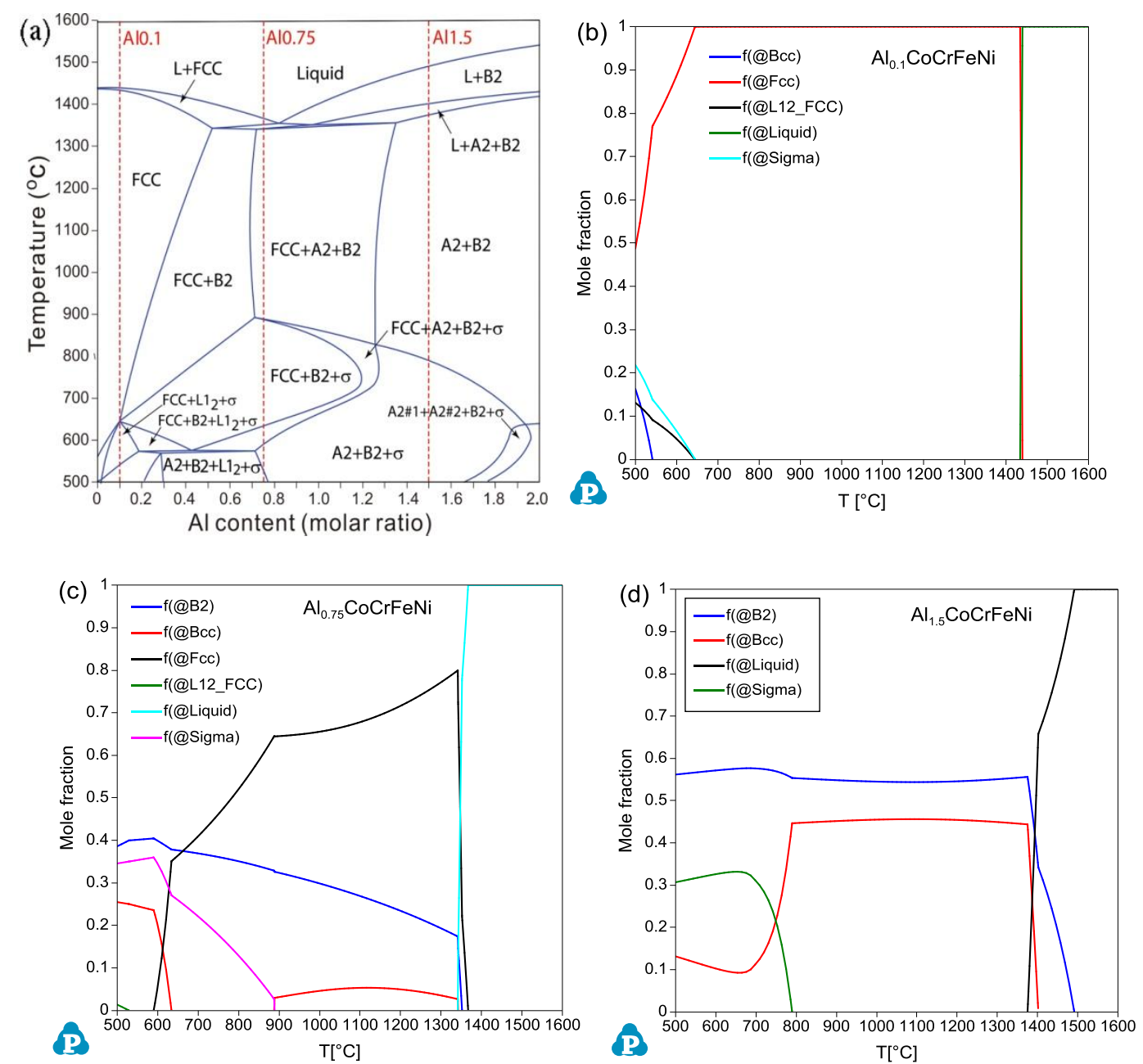

Fig. 5. 


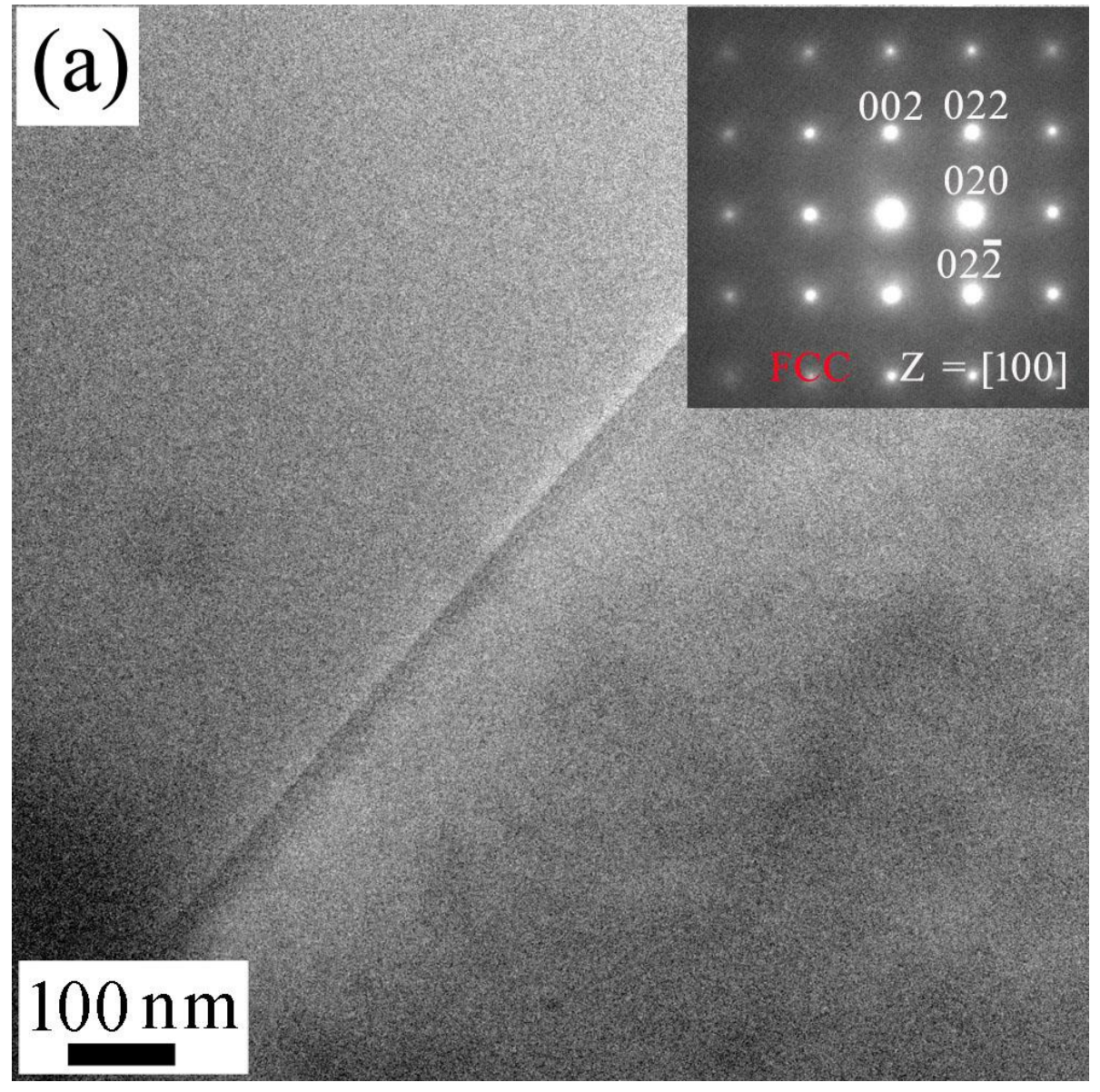




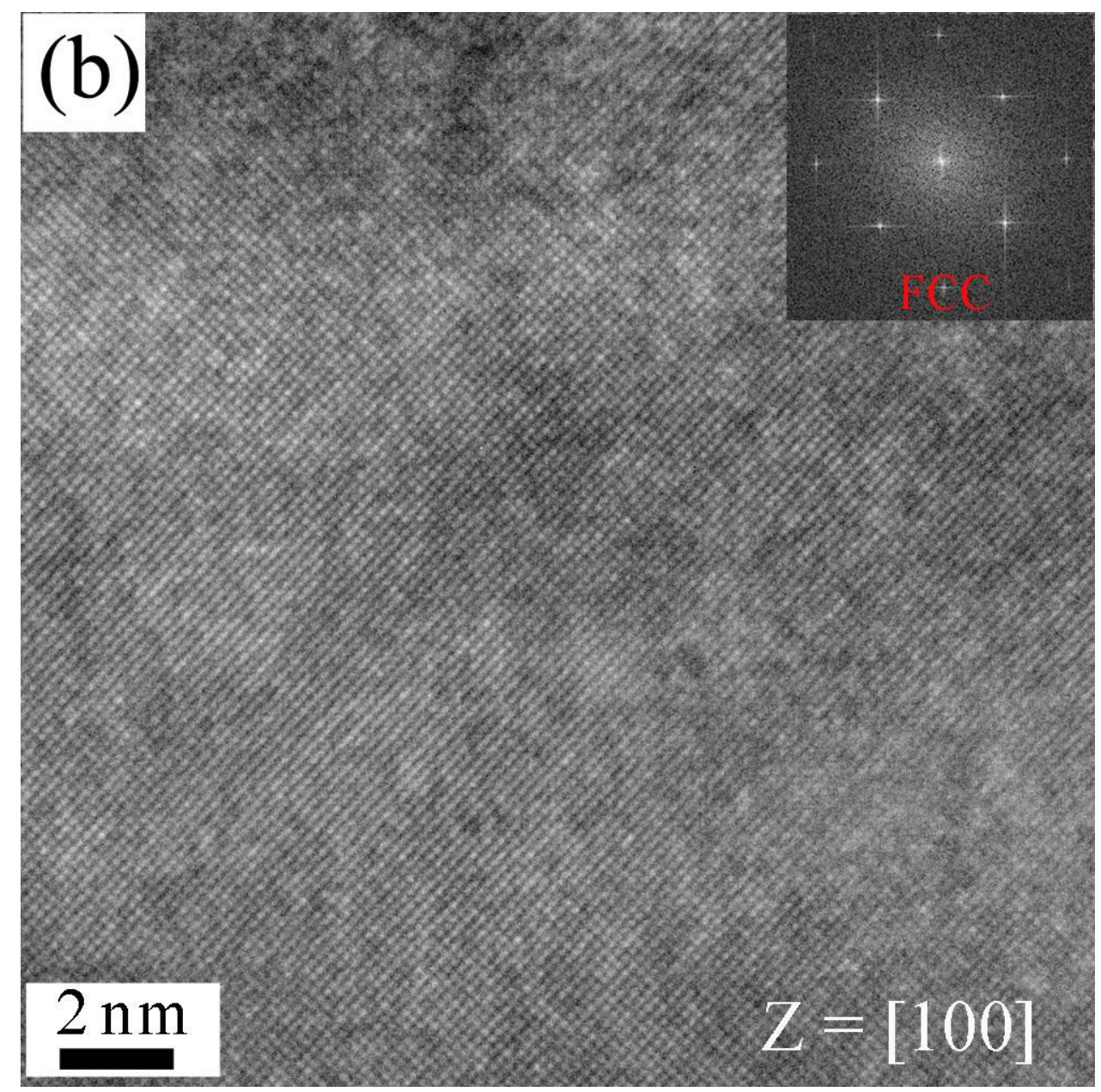




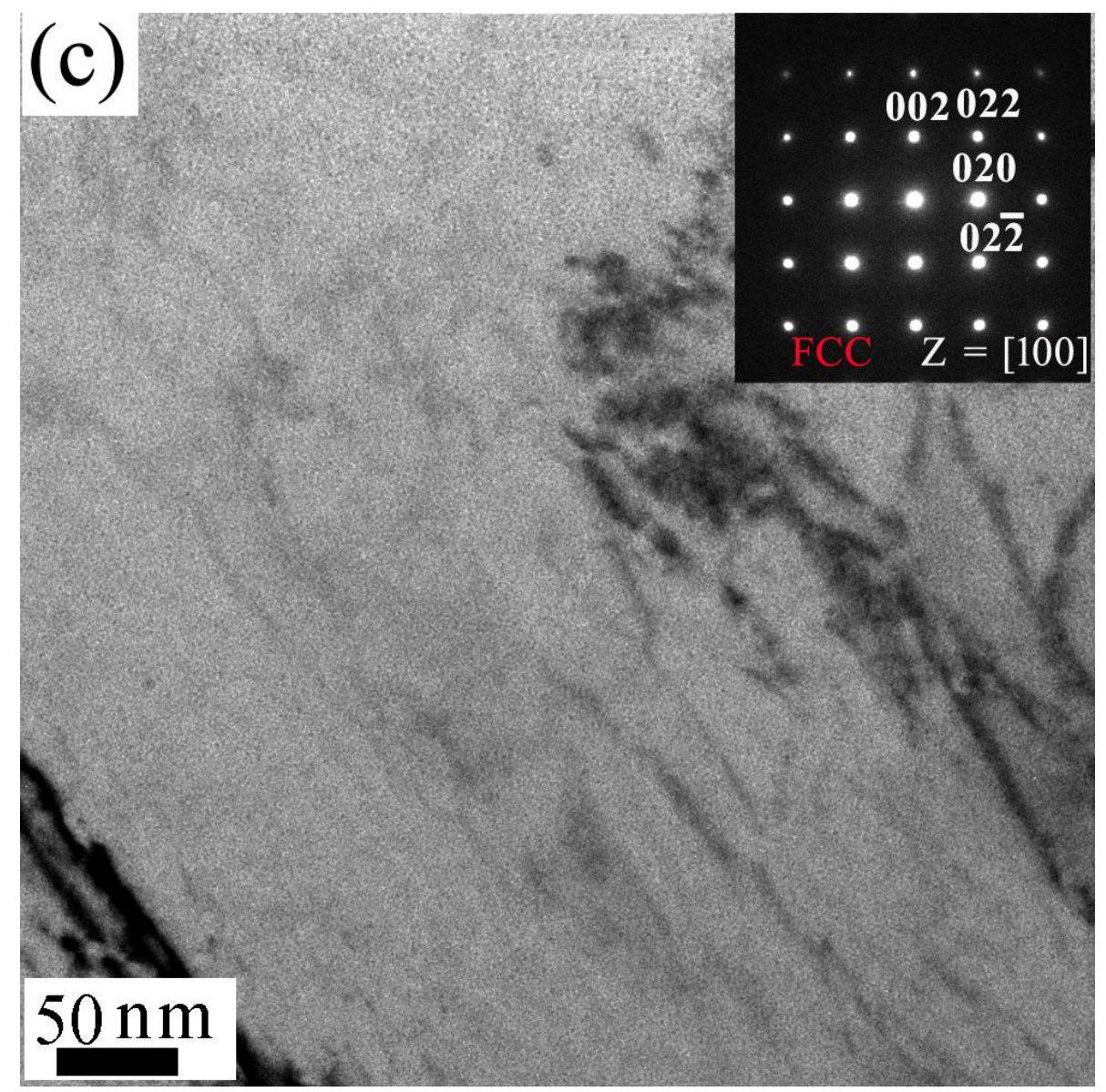




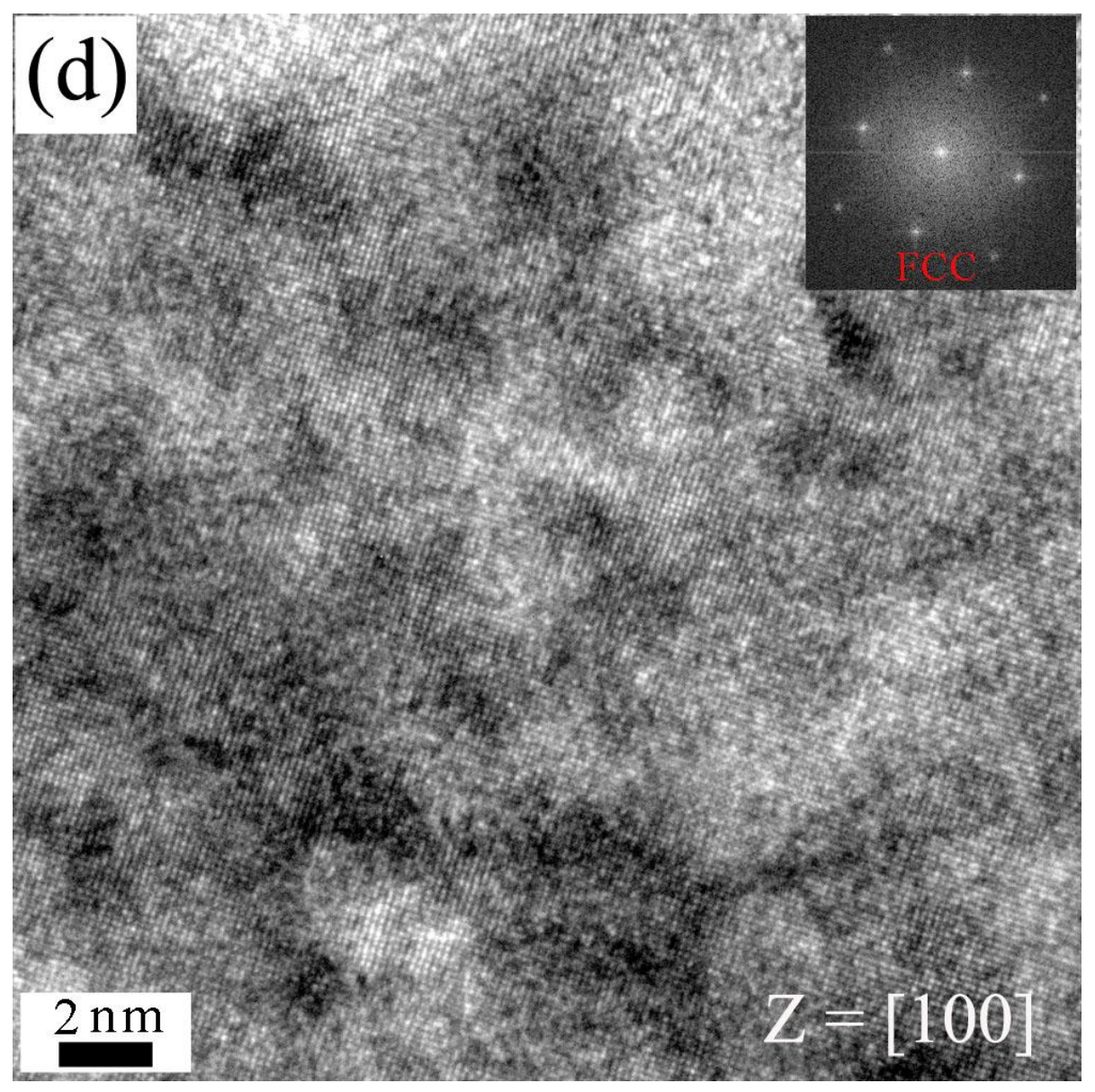


Fig. 6.

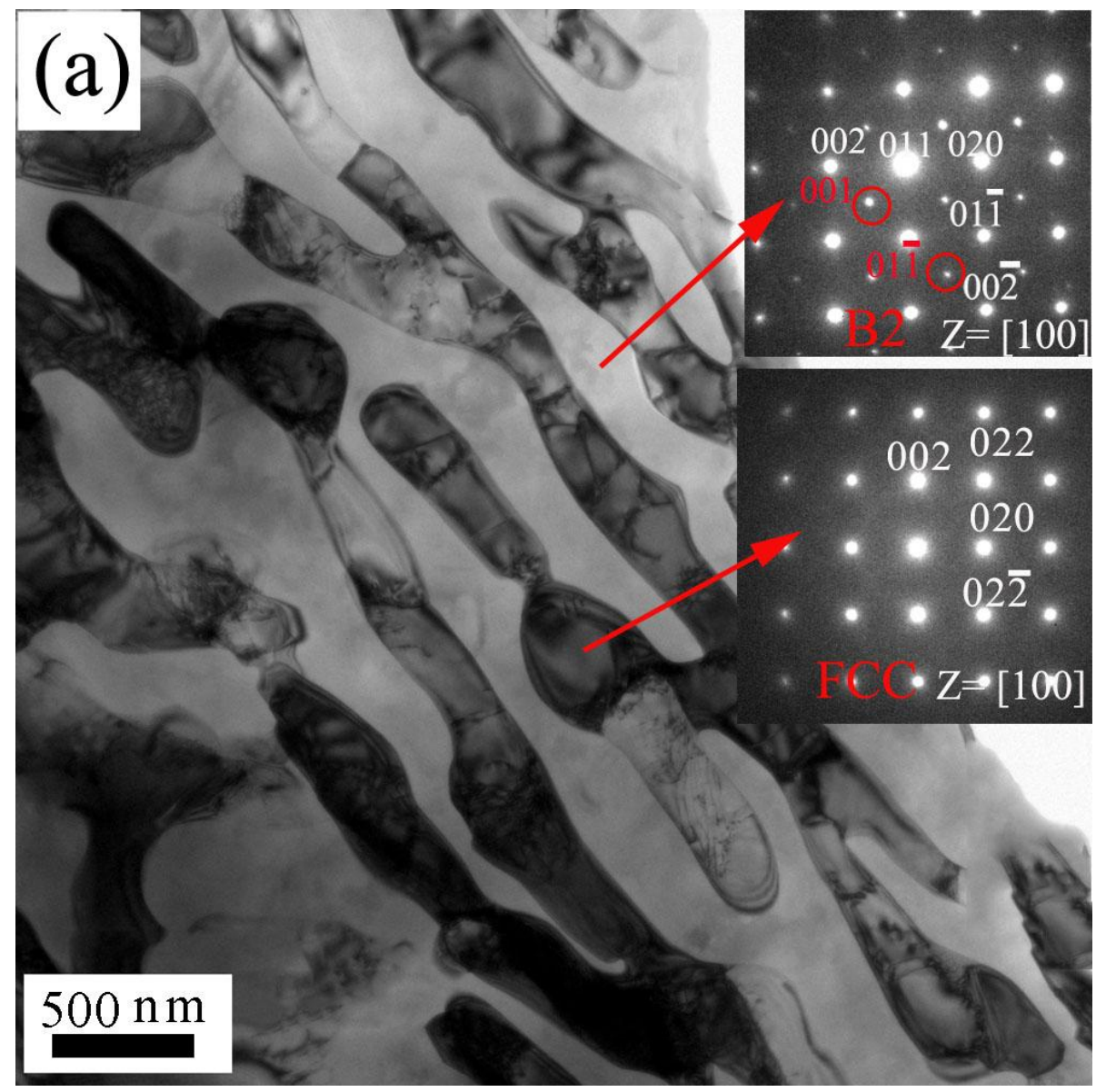




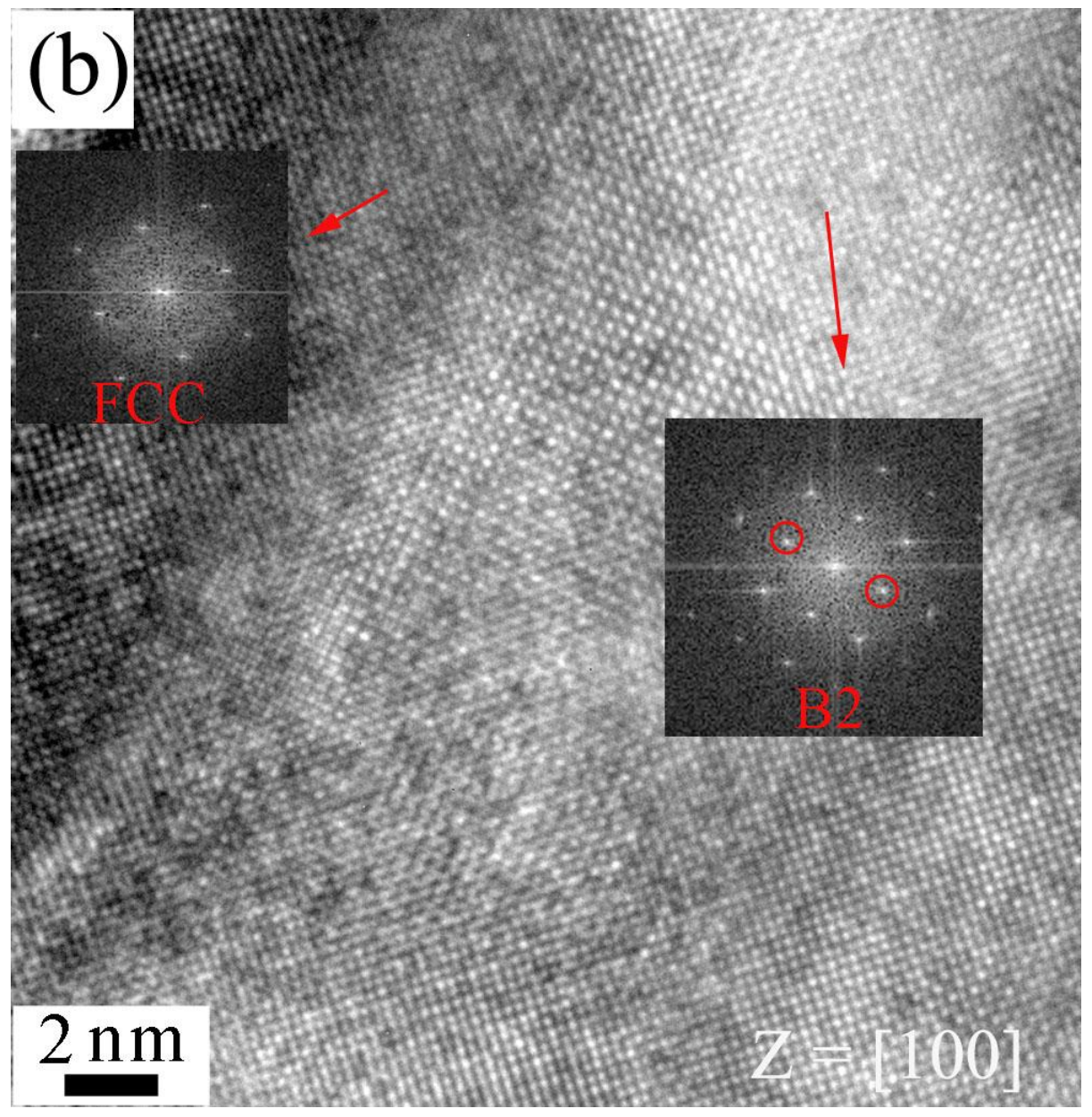




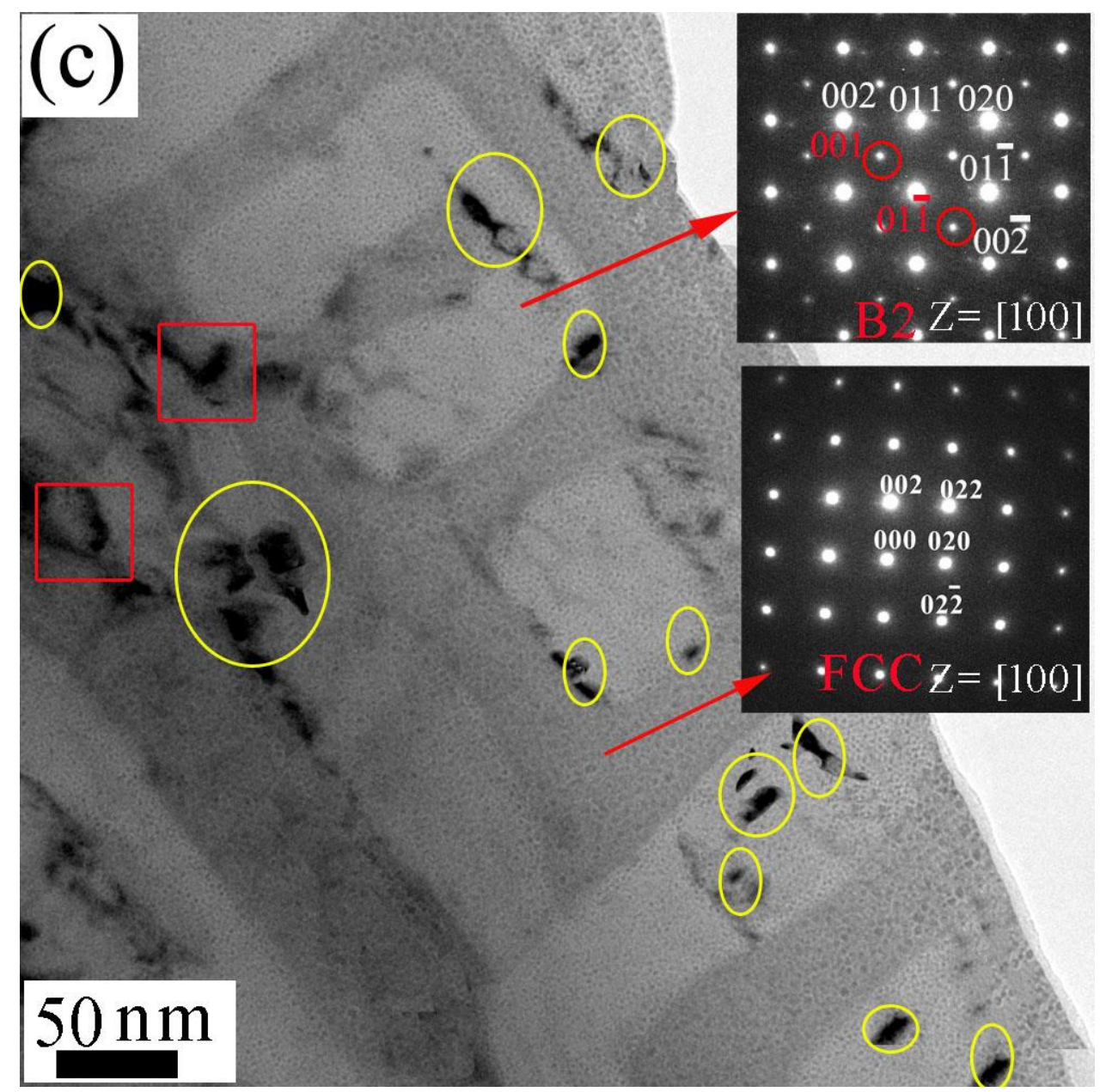




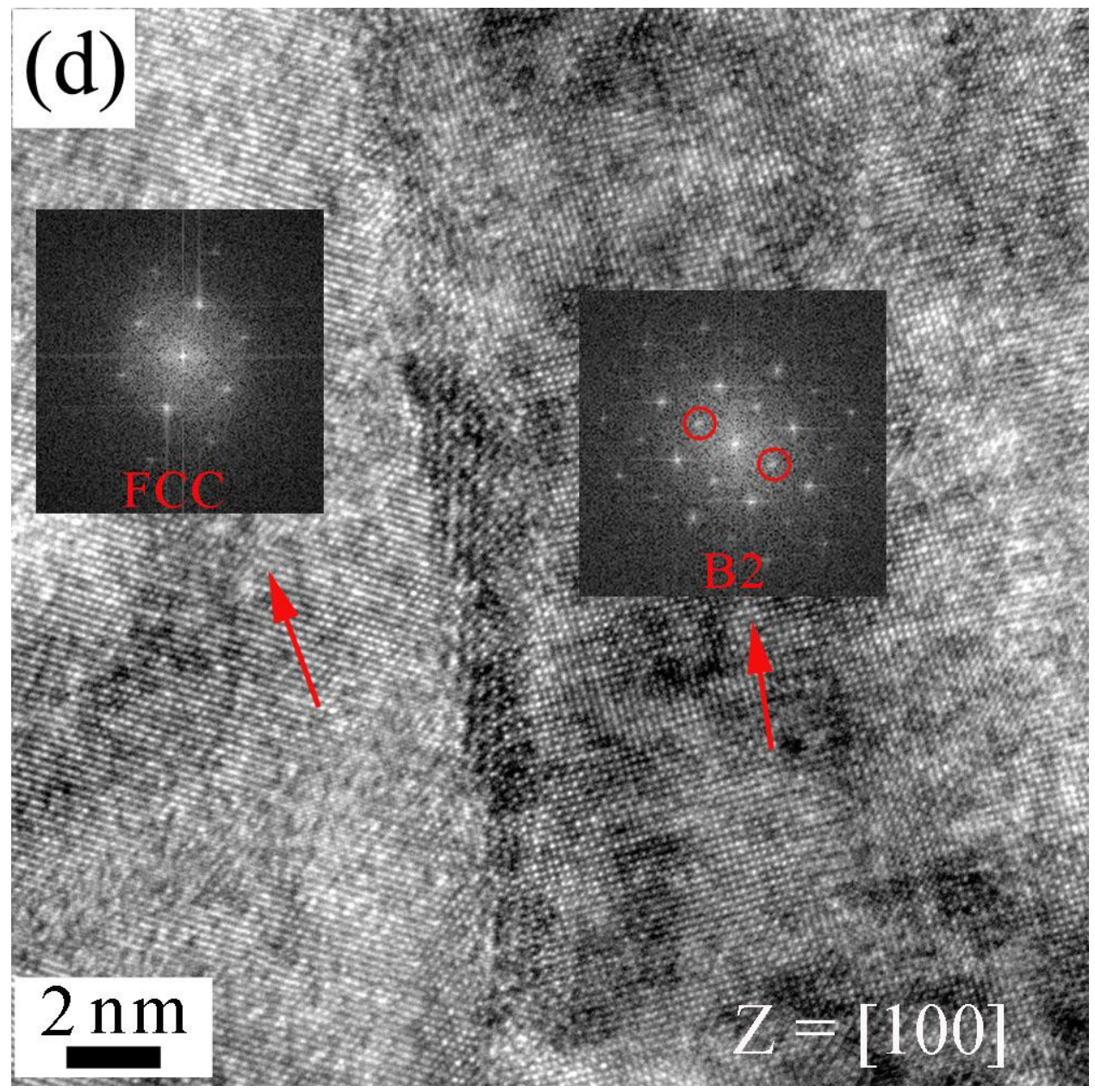




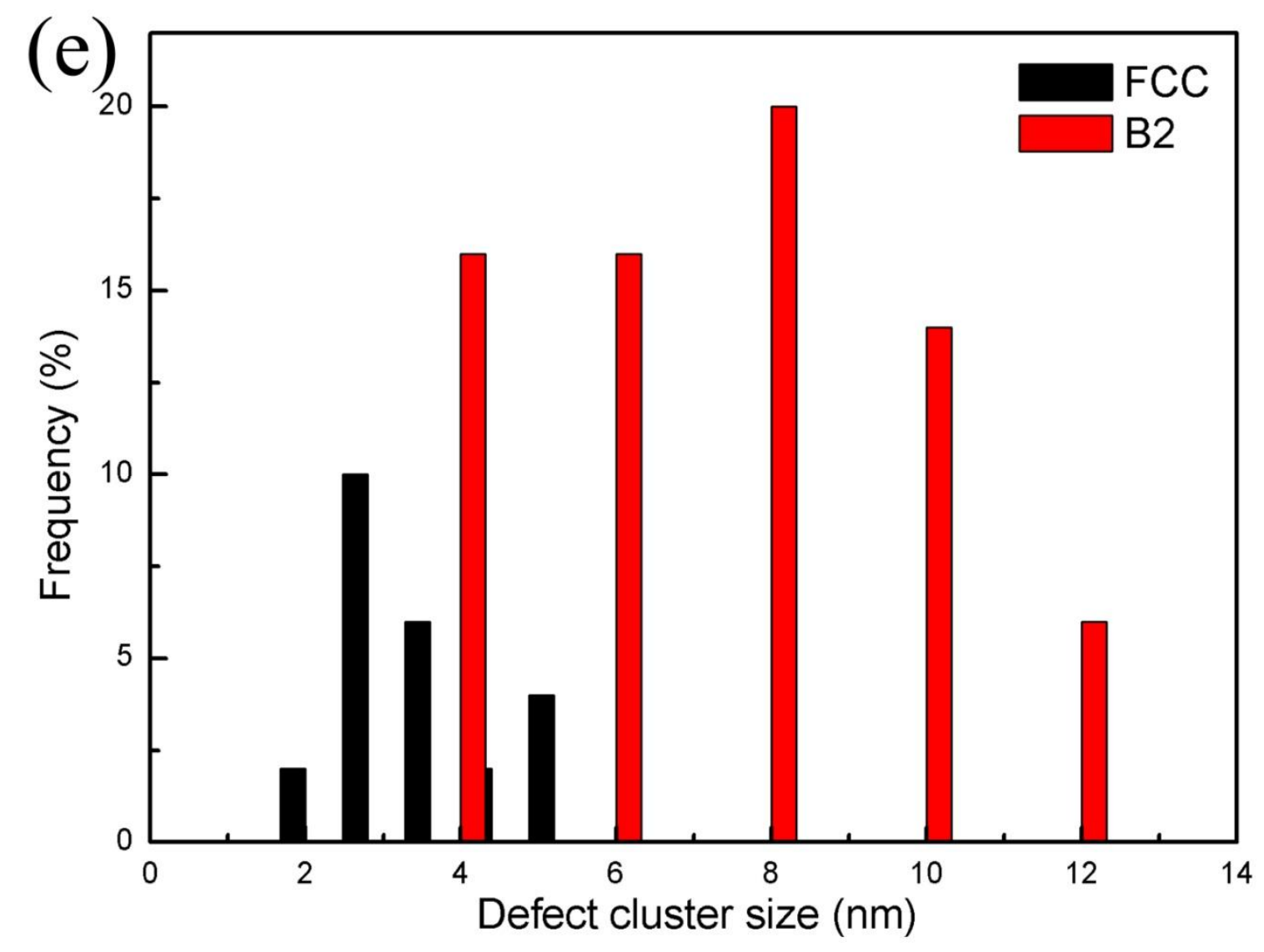


Fig. 7.

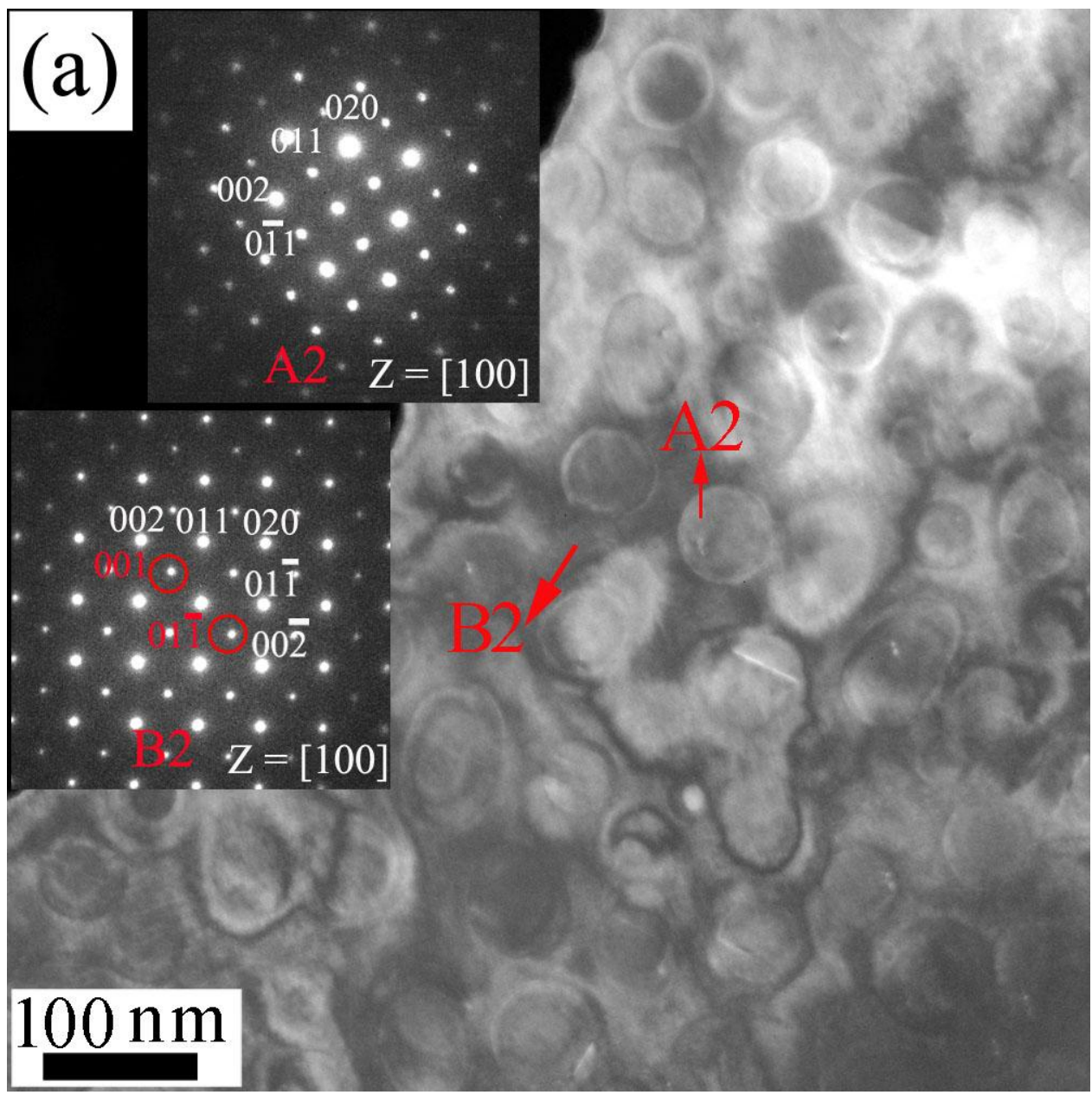




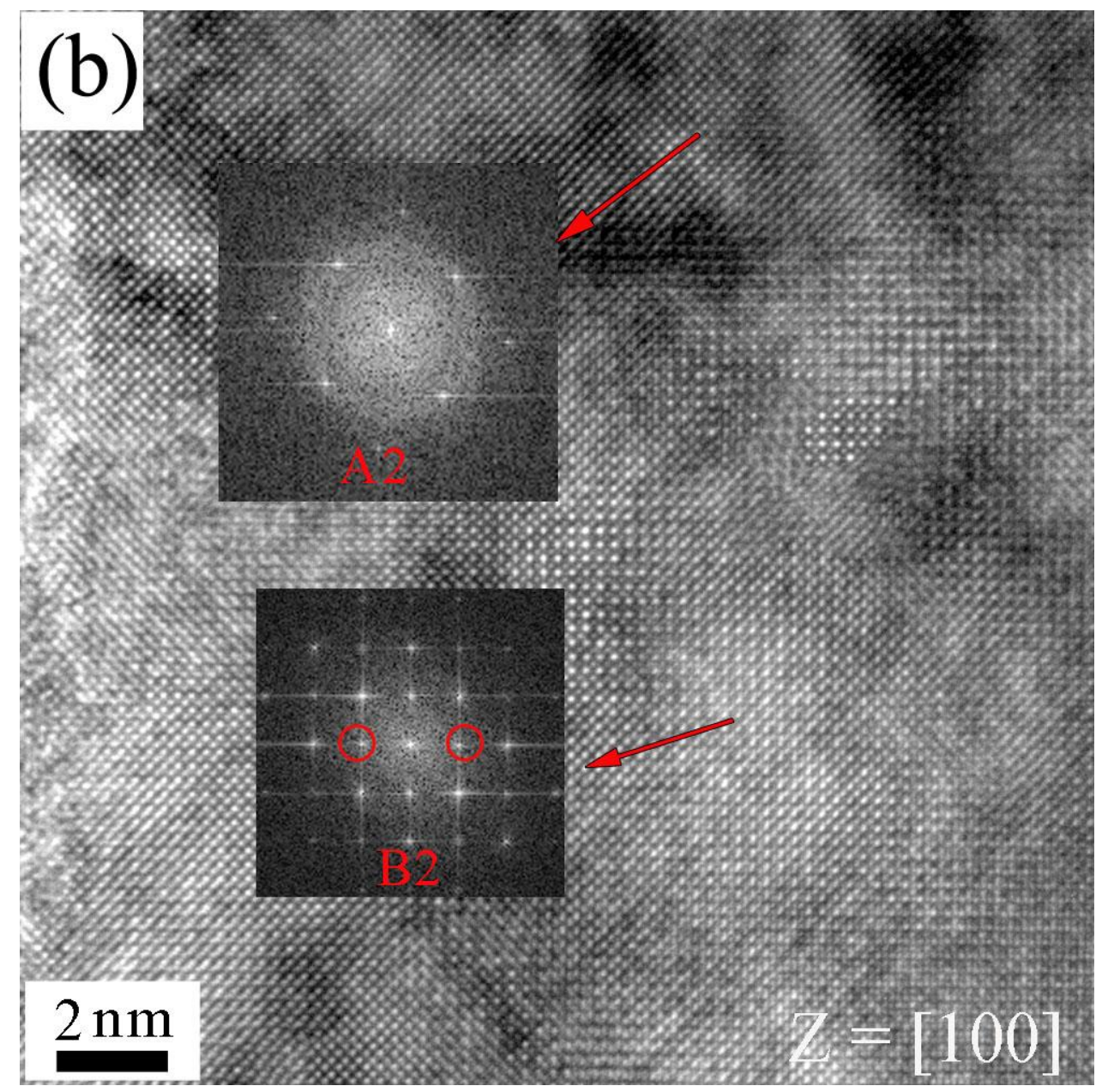




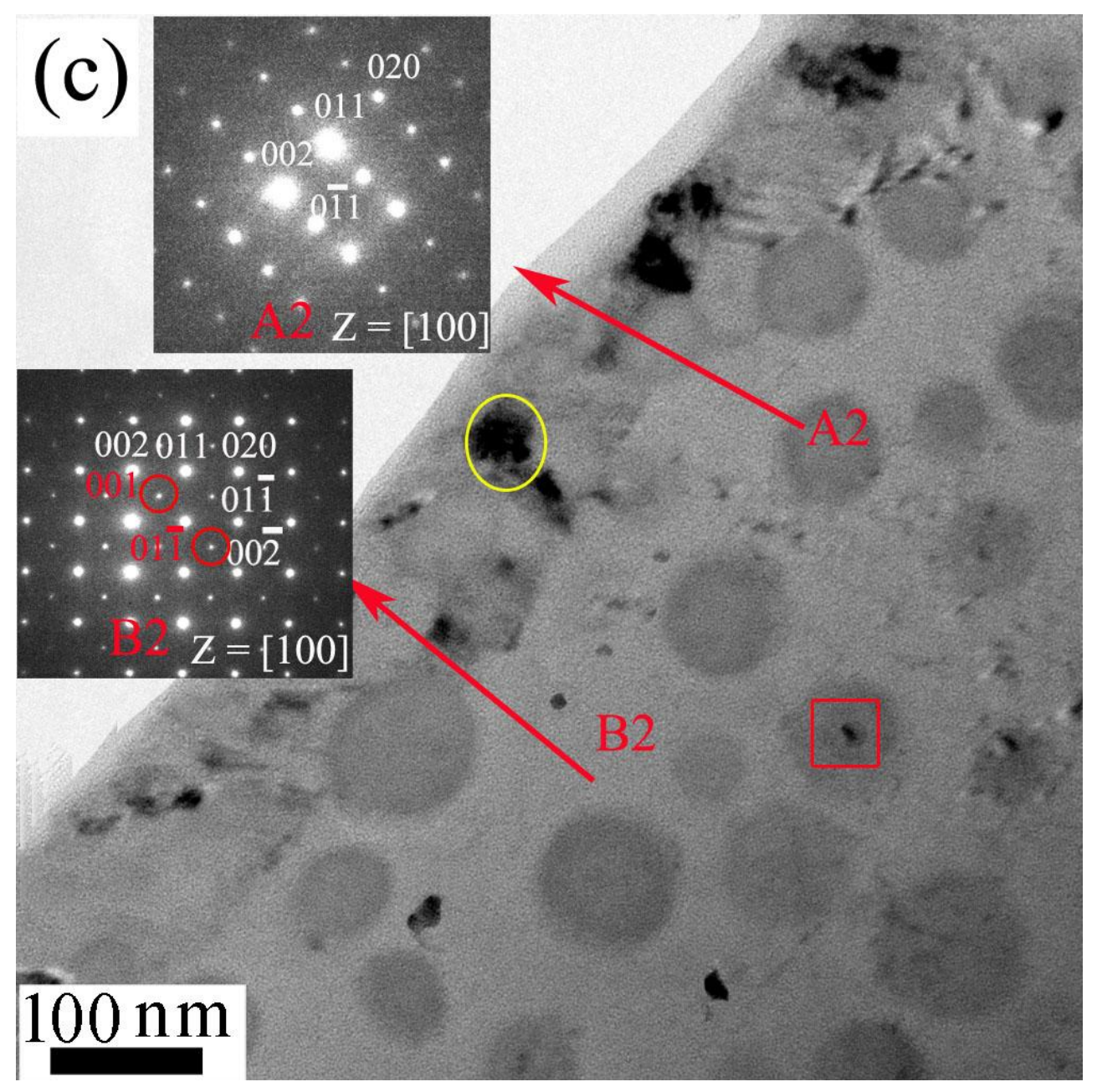




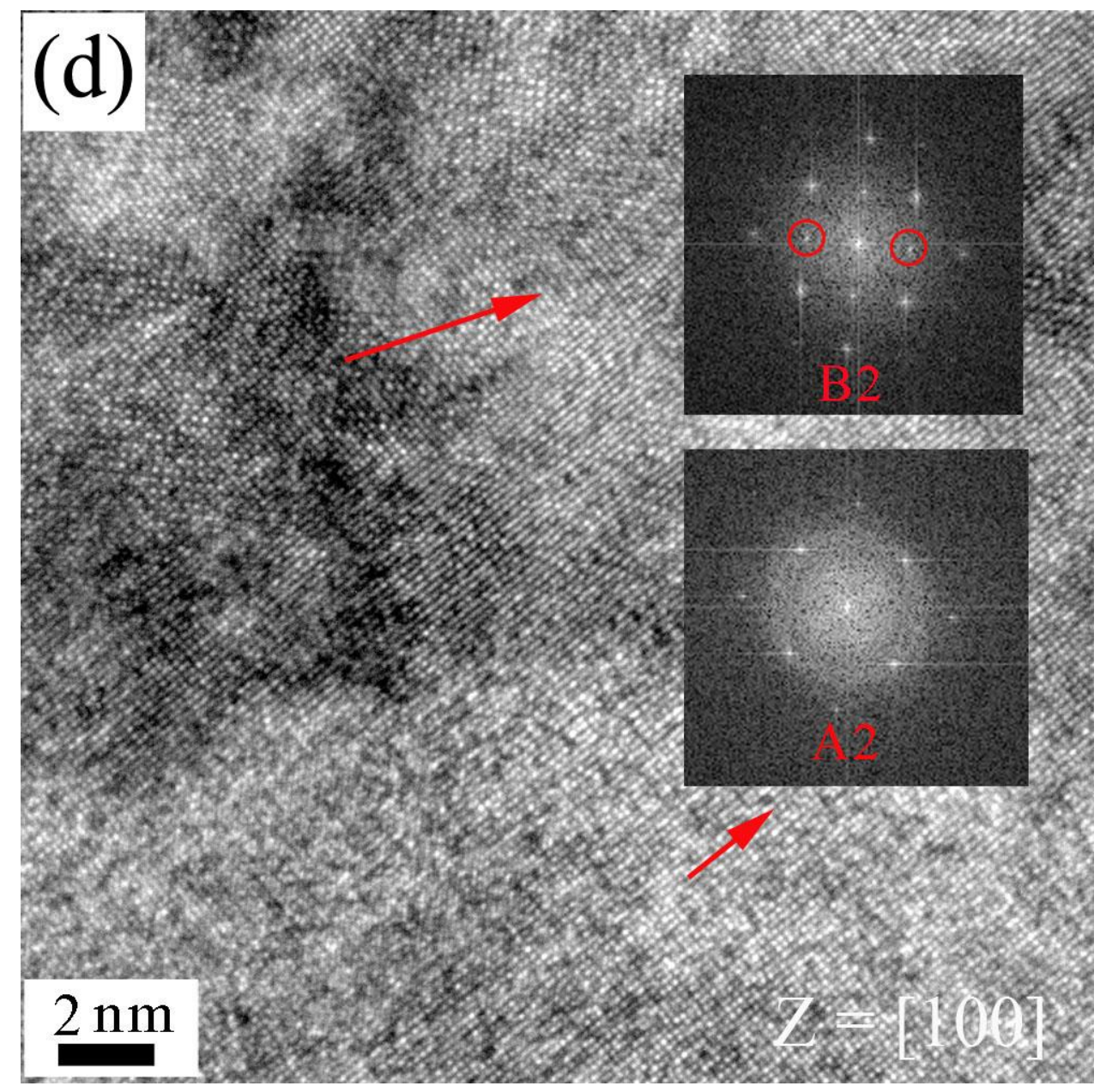




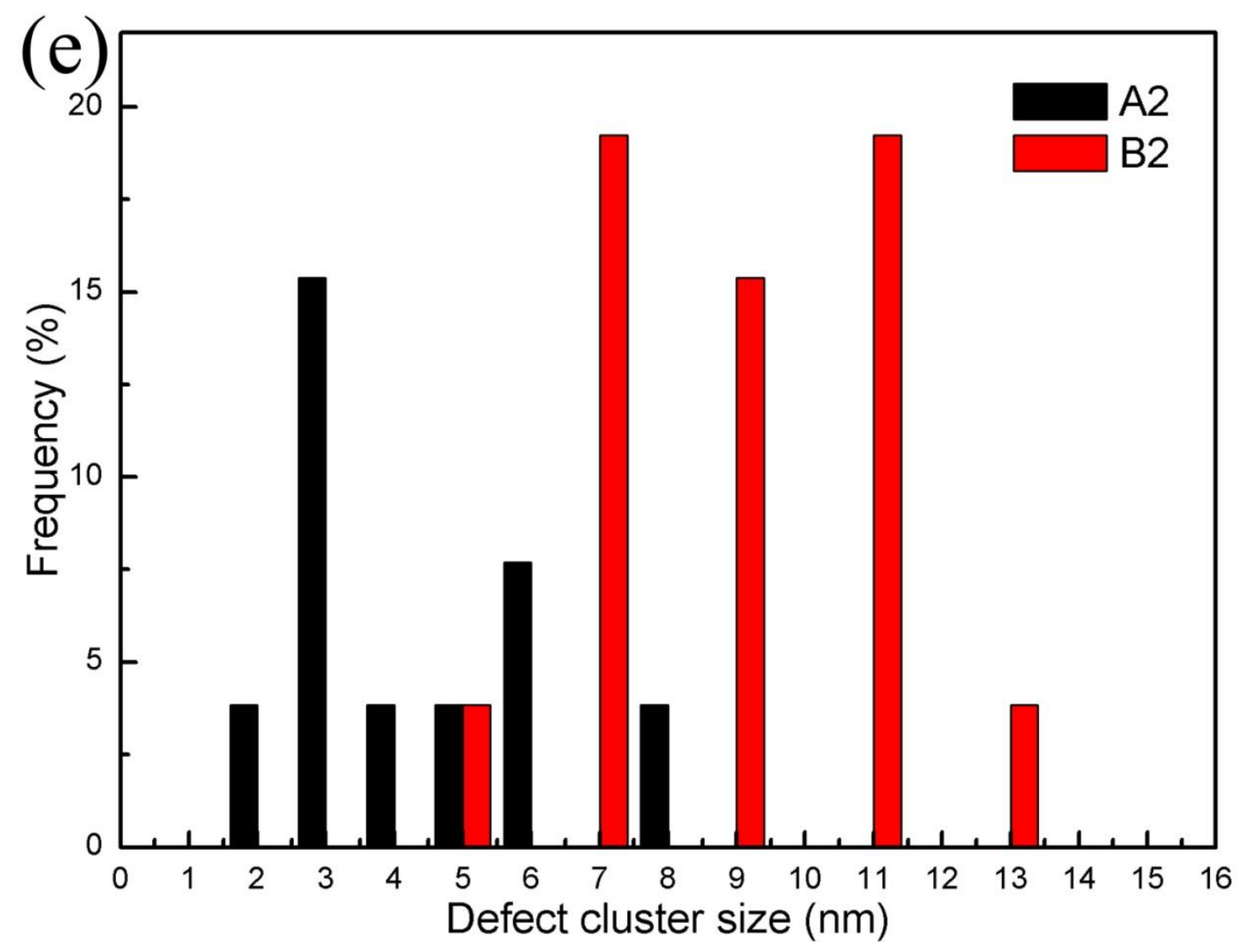

